\title{
An HIV-induced mechanism for T cell quiescence and proviral latency
}

\section{Saba Valadkhan ( $\nabla$ saba.valadkhan@case.edu )}

Case Western Reserve University https://orcid.org/0000-0002-6859-4883

\section{Leah Plasek}

Case Western Reserve University https://orcid.org/0000-0002-0161-3277

\section{Lalith Gunawardane}

Case Western Reserve University

\section{Farshad Niazi}

Case Western Reserve University

\section{Sara Mason}

Case Western Reserve University

\section{Konstantin Leskov}

Case Western Reserve University

\section{Gani Perez}

National Institutes of Health https://orcid.org/0000-0002-9133-6057

\section{Curtis Dobrowolski}

Georgia Institute of Technology

\section{Meenakshi Shukla}

Case Western Reserve University

\section{William Nutt}

University of Washington

Jonathan Karn

Case Western Reserve University

\section{Biological Sciences - Article}

Keywords: HIV, latency, quiescence, KLF2, MYC, p53, single cell RNA-seq, RNA-seq, CD4+ T cells, ex vivo models.

Posted Date: July 14th, 2021

DOI: https://doi.org/10.21203/rs.3.rs-654918/v1

License: (9) This work is licensed under a Creative Commons Attribution 4.0 International License. 



\section{An HIV-induced mechanism for T cell quiescence and proviral latency}

Short title: HIV infection induces quiescence and latency in infected CD4+ T cells

Leah M. Plasek ${ }^{1,++}$, Lalith S. Gunawardane ${ }^{1,++}$, Farshad Niazi ${ }^{1}$, Sara Mason ${ }^{1}$, Konstantin Leskov ${ }^{1}$, Gani Perez $^{2}$, Curtis Dobrowolski ${ }^{3}$, Meenakshi Shukla ${ }^{1}$, William S. Nutt ${ }^{4}$, Jonathan Karn ${ }^{1}$, and Saba Valadkhan $^{1 *}$

${ }^{1}$ Department of Molecular Biology and Microbiology, Case Western Reserve University School of Medicine, Cleveland, Ohio 44106, USA.

${ }^{2}$ Present address: Section of Molecular Neurogenetics, Medical Genetics Branch, National Human Genome Research Institute, National Institutes of Health, Bethesda, MD 20892-3708, USA.

${ }^{3}$ Present address: Department of Biomedical Engineering, Georgia Institute of Technology, Atlanta, GA 30332, USA

${ }^{4}$ Present address: Molecular \& Cellular Biology Program, University of Washington, Seattle, Washington 98195, USA.

${ }^{++}$These authors contributed equally to this work.

Further information and requests for resources and reagents should be directed to and will be fulfilled by the Lead Contact, Saba Valadkhan (saba.valadkhan@case.edu).

\section{Keywords}

HIV, latency, quiescence, KLF2, MYC, p53, single cell RNA-seq, RNA-seq, CD4+ T cells, ex vivo models. 


\section{Abstract}

HIV persists in infected individuals despite effective antiretroviral therapy due to the rapid establishment of a latent HIV reservoir, mainly composed of quiescent memory CD4+ T cells ${ }^{1-3}$. The mechanisms governing the formation of the latent reservoir remain poorly understood. It is commonly assumed that entry of HIV into latency is a rare and random event associated with sporadic infection of effector T-cells transitioning to a memory phenotype ${ }^{4-8}$. Using human primary CD4+ T cell models, we show instead, that HIV infection itself triggers a strong transcriptomic remodeling that results in activation of a quiescence program, including downregulation of cellular proliferation and metabolic pathways. This transcriptional program is initiated by KLF2, a key regulator of quiescence, along with activation of the p53 pathway and downregulation of MYC. Loss and gain of function studies confirmed that KLF2 and p53 signaling are responsible for the downregulation of MYC and proliferation pathways, and consequently, proviral transcriptional silencing. Thus, HIV infection per se, enhances the formation of the latent reservoir in T-cells, ensuring viral persistence in infected individuals. These findings identify a new and unexpected mechanism for the formation of the latent HIV reservoir, and broaden the repertoire of strategies through which viruses can control the host cell to their advantage.

\section{Main}

The cessation of antiretroviral therapy in HIV infected individuals is almost invariably followed

5 within weeks by return of viremia due to activation of a persistent and latent reservoir of HIV-infected cells ${ }^{1-3}$. Eradication of these latently infected cells, which largely consist of memory CD4+ T cells, microglia and to a smaller extent, macrophages, requires the development of novel therapeutic strategies $^{9-11}$. The majority of the latent reservoir is found in quiescent memory CD4+ T cells ${ }^{4-6}$. Recent studies have shown that during the transition from proliferating effector to quiescent memory cells,

remodeling of the cellular gene expression program facilitates the entry of an integrated provirus to latency ${ }^{4-8}$. While entry into quiescence is thought to play a dominant role in induction of proviral latency, additional mechanisms, such as direct infection of resting cells ${ }^{4,6,12}$, the genomic locus of the provirus $^{4,6,13-15}$, stochastic fluctuations in the expression of the viral Tat protein and cellular genes such as $\mathrm{KAP}^{16-18}$ also help regulate proviral entry into latency.

The mechanism(s) involved in entry of HIV infected cells into quiescence and their impact on proviral transcription remain largely unstudied. A number of transcription factors have been implicated in induction and maintenance of quiescence in uninfected cells, including key regulatory factors KLF2 
(Kruppel-like factor 2), a zinc finger transcription factor ${ }^{19}$ and the p53-induced gene TOB1 (Transducer Of ERBB2-1 ${ }^{20-22}$. Both proteins are known to be highly expressed in quiescent cells, and upon

20 activation of $\mathrm{T}$ cells, their cellular levels are strongly downregulated to nearly undetectable levels ${ }^{20-22}$, but direct evidence that they play a regulatory role in primary human T-cells in lacking. TOB1 appears to partly mediate the cell cycle arrest caused by activation of $\mathrm{p} 53^{23}$, pointing to a potential role for the p53 signaling cascade during T cell quiescence. Overexpression of KLF2 in human CD4+ T cell lines and in vivo in the mouse rapidly led to a marked downregulation of MYC, followed by cellular

25 quiescence characterized by inhibition of proliferation, decreased cell size, and reduction in cellular activation markers ${ }^{20,21}$. Similarly, KLF2 loss of function studies in vitro and in vivo in the mouse $T$ cells led to spontaneous entry into $S$ phase, an activated phenotype with increased cell size and expression of proliferation markers and a high level of apoptotic death that mimicked activation-induced cell death $^{20,24}$. The pro-quiescence impact of KLF2 could be rescued by expression of MYC in Jurkat 30 cells $^{20,21}$. Further, expression of a dominant negative MadMyc fusion protein could largely recapitulate the impact of KLF2 overexpression in Jurkat cells ${ }^{20}$. Together these results indicate that KLF2 is a powerful inducer of quiescence in CD4+ T cells acting at least partly through downregulation of MYC expression. However, key questions such as whether the same factors are involved in induction of quiescence in infected cells and the conditions in which the quiescence program is activated in 35 productively infected cells remain unanswered.

We analyzed global gene expression changes during HIV life cycle using recently-developed ex vivo latency models of primary human CD4+ $\mathrm{T}$ cells (QUECEL), which provide highly pure, homogeneous populations of Th1, Th2, Treg and Th17 polarized, HIV infected cells using a minimally disturbing purification strategy via a CD8-EGFP fusion protein ${ }^{8}$. We performed RNA-seq on untreated,

40 vector-infected (+vector) and purified HIV infected (+HIV) cells under proliferative conditions 72 hours post infection (72 hpi); two weeks after the addition of quiescence-inducing cytokines when full quiescence and proviral latency are achieved; and 24 hours after reactivation through TCR stimulation (aTCR 24h)(Extended Data Fig. 1A, B) ${ }^{8}$. Dimensionality reduction studies indicated that within the quiescent and aTCR 24h groups, the uninfected, +vector and +HIV cells clustered together, indicative

45 of very similar global gene expression patterns (Fig. 1B) which was further confirmed by differential gene expression studies (Extended Data Fig. 2A) and is consistent with published data ${ }^{25,26}$. Both dimensionality reduction and differential expression studies on uninfected versus +vector cells in proliferating state indicated that these two cellular populations were essentially identical in terms of gene expression pattern (Fig. 1B, Extended Data Fig. 2A, B). In contrast, +HIV 72 hpi formed a 50 distinct cluster (Fig. 1B), suggesting strong virally-induced changes to the transcriptome which was 
confirmed by differential gene expression studies (Extended Data Fig. 2A). Th1, Th2, Th17 and Treg polarized cells showed virtually identical change in gene expression pattern in the above studies regardless of polarization identity (Fig. 1A, Extended Data Fig. 1B).

The use of QUECEL models allowed, for the first time, the investigation of the poorly 55 understood process of entry of primary human CD4+ T cells into quiescence at high transcriptomic resolution. Distinctive gene signatures for the quiescence state that were shared among uninfected, +vector and + HIV quiescent cells included the strong upregulation of KLF2, TOB1 and CDKN2B, known pro-quiescence regulatory factors and quiescence markers (Fig. 1C). By contrast, multiple pathways, including MYC signaling and MTORC pathways, both of which are known to be key drivers

60 of the $T$ cell proliferative phase ${ }^{27}$, were downregulated, along with pathways related to cell cycle, transcriptional and translational regulation and cellular metabolism (Fig. 1D, E, Extended Data Fig. 3A). Similarly, genes known to be up- or down-regulated during entry into quiescence, based on mSigDB gene sets and published studies $^{28}$, overwhelmingly showed differential regulation in the expected direction during entry of uninfected cells into quiescence in QUECEL models (Extended Data

65 Fig. 3B), further confirming the quiescent identity of these cells.

These changes in gene expression were largely reversed after TCR stimulation. Most genes downregulated during entry into quiescence were upregulated after reactivation and vice versa (Extended Data Fig. 3C). The vast majority of genes differentially expressed following TCR stimulation were upregulated, indicating a global rise in transcriptional activity (Extended Data Fig. 2A). The

70 upregulated genes and pathways included several cellular growth and proliferation markers and pathways, including MYC and E2F signaling, while quiescent markers were downregulated during this transition (Fig. 1C, Extended Data Fig. 3D,E). However, a number of additional pathways such as TNF and IL2-STAT5 signaling, which were not enriched during entry into quiescence, were among the reactivation-induced gene sets (Extended Data Fig. 3D,E).

\section{HIV infection leads to transcriptomic changes identical to those observed in quiescent cells}

Unexpectedly, both dimensionality reduction studies and Jensen-Shannon divergence calculations (Fig. 1A, B) showed that +HIV 72 hpi cells (Extended Data Fig. 4A) clustered close to quiescent cells. Compared to uninfected and +vector 72 hpi cells maintained in the same proliferation-

80 supporting media, +HIV 72 hpi cells showed a predominant pattern of transcriptional downregulation, with over 1150 and 2400 protein-coding genes being up and downregulated, respectively (Extended Data Fig. 2A). 
The cellular pathways altered after HIV infection (Fig. 2A, Extended Data Fig. 4B) closely resembled those that were downregulated after entry into quiescence in uninfected and +vector cells

85 (Fig. 2A, 1D). Among the $\sim 3300$ protein-coding genes that were differentially expressed in both uninfected and +vector cells when entering quiescence, over 2650 showed a correlated change in expression in +HIV 72 hpi cells (Extended Data Fig. 4C), further demonstrating strong similarities between quiescence and $72 \mathrm{~h}$ post-HIV infection gene expression patterns.

Bolstering the above results, the HIV-downregulated pathways correspond to key proliferative 90 pathways, including both MYC and mTORC1 signaling, consistent with reduced transcriptional and translational activity. Metabolic pathways such as glycolysis, adipogenesis and oxidative phosphorylation similarly showed reduced activity (Fig. 2A, Extended Data Fig. 4B). Pathways regulated by E2F and HIF1A (hypoxia-related pathways), also major players in the T cell proliferative state $^{29,30}$, were likewise downregulated (Fig. 2A, Extended Data Fig. 4B), despite the fact that the $+\mathrm{HIV}$

9572 hpi cells were maintained in proliferation-supporting media containing a high level of IL2, a known inducer of proliferation in T cells. Thus, acutely HIV infected cells showed an unexpected pattern of metabolic and transcriptional shutdown and based on downregulation of MTOR, likely translational repression. In contrast, upon addition of quiescence-inducing cytokines to the +HIV cells (Extended Data Fig. 1A), entry into full-quiescence state is accompanied by relatively mild changes in key cellular

100 proliferative and metabolic pathways (Fig. 2A, compare lanes labeled +HIV quiescent and +vector quiescent, also see Extended Data Fig. 2A, 4D, E). Consistent with pathway analysis patterns, the number of genes differentially expressed during transition of +HIV 72 hpi cells to full quiescence is small relative to the magnitude of change during entry of +vector $72 \mathrm{hpi}$ cells into quiescence (Extended Data Fig. 2A). As the fully quiescent +HIV and +vector cells are largely identical in terms of

105 their gene expression pattern as shown by the very small number of genes $(<500)$ differentially expressed between the two (Extended Data Fig. 2A, also see Fig. 1B), these results indicate that after 72 hours of HIV infection, the cells have already undergone a large fraction of transcriptomic changes needed to achieve the fully quiescent state.

In summary, RNA-seq results indicate that HIV infection led to increased expression of key 110 quiescence markers KLF2, TOB1, and CDKN2B, along with a reduction in the level of proliferation markers such as CD25/IL2RA, CD71/TFRC and MYC (Fig. 1C, see also Extended Data Fig. 4F). Validating these unexpected results, a FACS study of markers of proliferation cyclin D3 and Ki67 showed a correlated decrease in protein level in unpurified, minimally disturbed HIV infected cells compared to uninfected cells starting as early as 2 days post infection (Fig. 2B, Extended Data Fig. $1154 G$ ). Similarly, analysis of the rate of growth of +vector 72 hpi and +HIV 72 hpi cells showed a 
reduction in cellular growth starting 2 days after HIV infection which reflected the ratio of infected cells in the population (Fig. 2C, Extended Data Fig. 4G). As can be seen in Extended Data Fig. 5A, B and C, similar to the case with +vector quiescent cells (Extended Data Fig. 3B), the gene expression pattern of +HIV 72 hpi cells closely reflected the transcriptomic signature of quiescent state.

\section{HIV infection leads to a block to MYC signaling, a key proliferative factor in CD4+ T cells}

We evaluated the pattern of enrichment of transcription factor binding sites near the promoters of genes differentially expressed after HIV infection, which pointed to strongly significant reduction in expression of genes with binding sites for the two major proliferative transcription factors in CD4+ T cells, MYC and E2F (Fig. 2D, Extended Data Fig. 6A). The temporal pattern of gene expression

125 changes in response to HIV infection and during entry into full quiescence indicated that a number of key proliferative regulatory pathways and genes, most prominently MYC target genes and MYC itself, show a strong and rapid downregulation predominantly in early time points (within 72 hours) after HIV infection (Extended Data Fig. 6B-E). A second group of regulatory pathways and genes, such as cyclins and E2F family genes and pathway, are predominantly downregulated in later time points

130 (days 4-14 after HIV infection), including during entry into full quiescence after the addition of quiescence-inducing cytokines (Extended Data Fig. 6C-F). Among the upregulated pathways, the p53 pathway and its downstream signaling pathway of Wnt/beta catenin ${ }^{31,32}$ were among the "early" responding group. Further, several pro-quiescence genes including KLF2, CDKN2B, CDKN1A, SMPD3 and SMAD3 were also predominantly or exclusively induced in early time points after HIV

135 infection (Extended Data Fig. 6E). Altogether, these data suggest that the majority of the upstream signaling events of the quiescence program were already set in motion within 72 hours post HIV infection, with the gene expression changes at the later time points corresponding to the downstream results.

Although the impact of HIV infection on the induction of the transcriptional program of 140 quiescence has been previously overlooked, individual aspects of this phenotype had been noted in literature including reduced expression of genes associated with activated state in CD4+ T cells ${ }^{31,33}$, suppression of transcription, RNA processing ${ }^{34}$, translation ${ }^{35}$, metabolism, proliferation-related pathways and cellular growth rate ${ }^{36,37}$. To determine the reproducibility and generality of our findings, we used multiple independently-performed RNA-seq studies involving early HIV infection from public

145 databases (Table S1) in which high levels of infection were achieved using different strains of replication-competent HIV from LAI and NL4-3 clones $^{31,33,35,38,39}$ and primary HIV isolates ${ }^{34,36}$, which were used to infect diverse CD4+ T cell lines and primary CD4 cells (Table S1). Our re-analysis of these independently-performed RNA-seq studies showed changes in key cellular pathways that were 
nearly identical to those found in our study. These included an upregulation of p53 pathway and 150 downregulation of critical proliferation pathways, most prominently MYC and E2F signaling and cell cycle-related pathways (Extended Data Fig. 6G). To determine whether the HIV-induced quiescence program was also observed in other reservoir cells, we re-analyzed an RNA-seq dataset focused on microglia ${ }^{40}$, the main reservoir cell type in the brain (Extended Data Fig. 7A-C). Interestingly, we observed nearly identical changes after HIV infection in microglia, suggesting a similar induction of the

155 dormant state after HIV infection in these cells, including the downregulation of MYC and E2F signaling (Extended Data Fig. 7A, B). Finally, we asked whether different polarized CD4+ T cells show the transcriptomic pattern of quiescence after HIV infection. While all tested polarized cells showed a strong downregulation of MYC signaling, E2F signaling was not a strong player in Th17 polarized cells (Extended Data Fig. 7D). Interestingly, it has been shown that MYC is a strong regulator of E2F

160 signaling ${ }^{41,42}$, and the much smaller magnitude of change in the expression level of the E2F family members that positively regulate $T$ cell proliferation (E2F1, 2 and 3$)^{43,44}$ compared to the level of MYC downregulation following HIV infection (Extended Data Fig. 6B, F, 7E) suggests that the changes in E2F signaling may be secondary to reduced level of MYC transcriptional activity.

To determine if downregulation of MYC alone could recapitulate the observed HIV-induced 165 changes in gene expression, we identified multiple independently performed, publicly available RNAseq studies of the impact of MYC knockdown (Table S2). Interestingly, in all cases, MYC knock down resulted in downregulation of E2F targets, in addition to multiple other proliferative pathways, resulting in a gene expression pattern that very closely mimicked that observed following HIV infection (Fig. 2E). Consistently, knock down of MYC in proliferative, uninfected T cells led to loss of proliferative

170 markers, similar to what was observed after HIV infection (Fig. 2F). Thus, downregulation of MYC was sufficient to largely recapitulate the gene expression pattern observed after HIV infection.

\section{Early activation of KLF2 and p53 signaling pathways downregulates MYC and initiates the program of quiescence}

To define the mechanism of MYC downregulation after HIV infection, we next investigated the 175 potential contribution of HIV-induced early activation of the p53 pathway, a known negative regulator of the expression of $\mathrm{MYC}^{45}$. Treating proliferating primary human CD4+ T cells with two known agonists of p53 pathway, RITA and nutlin ${ }^{46,47}$, led to p53 induction along with a concomitant slowdown in cellular proliferation and pronounced downregulation of proliferation markers within 24 hours (Fig. 3A-C, Extended Data Fig. 8A). RNA-seq study of the RITA-treated cells pointed to downregulation of 180 MYC and several MYC target genes (Fig. 3D, Extended Data Fig. 8B), albeit at a lower magnitude compared to what was observed following HIV infection, pointing to the involvement of additional 
factors in induction of the observed HIV-induced transcriptomic signature of quiescence.

To find potential candidate genes that may play such a role, we identified the HIV-induced genes which showed a negative correlation with MYC level (Fig. 3E). Interestingly, KLF2, a known

185 strong negative regulator of MYC and a key inducer of cellular quiescence in CD4+ T cells, was among the genes showing the strongest negative correlation with MYC in multiple studies both in the presence and absence of HIV (Fig. 3E, Extended Data Fig. 8C-G). Among the $\sim 100$ protein-coding genes which were consistently up or down-regulated after HIV infection in datasets shown in Extended Data Fig. 6G, the most upregulated gene was KLF2 (Fig. 3F), whereas MYC was among the genes 190 consistently showing a strong downregulation after HIV infection (Fig. 3F).

Time course studies in primary human CD4+ T cells following infection with the HIV reporter virus indicated that the level of KLF2 was significantly upregulated at $24 \mathrm{hpi}$ and showed further increase at $48 \mathrm{hpi}$ (Fig. 3G). Importantly, this increase was not a passive side effect of cellular stress but depended on integration of the HIV provirus into the genome, as the addition of raltegravir blocked 195 the rise in KLF2 levels (Fig. 3G). KLF2 knock down prevented entry into quiescence, even when the knock down cells were cultured in quiescence-inducing media (Fig. $3 \mathrm{H}, \mathrm{I}$ ). On the other hand, treatment of proliferating primary human CD4+ T cells with simvastatin, a known inducer of KLF2 ${ }^{48-50}$, led to a strong reduction in proliferative markers (Extended Data Fig. 8A), consistent with exit from proliferating state.

200 To complement the above studies, we also performed an unbiased shRNA screen against 15,000 cellular protein-coding genes to identify those involved in positive or negative regulation of HIV transcriptional activity ${ }^{51}$. Since proviral activation is strongly associated with the $\mathrm{T}$ cell activated state ${ }^{8}$, loss of function of factors involved in inhibiting $\mathrm{T}$ cell activation will yield positive hits in our screen. Interestingly, $\sim 40$ genes among those consistently up or down-regulated following HIV infection (Fig.

205 3F) were enriched in the shRNA screen, with KLF2 and MYC among the most positively and negatively enriched genes in this list, respectively (Extended Data Fig. 8H). CDKN1A/p21, a known p53 effector gene and a strong inducer of cell cycle arrest, was also among the positively enriched genes (Extended Data Fig. 8H). Interestingly, a recent shRNA screen study independently identified KLF2 as a key factor in maintenance of HIV latency ${ }^{52}$. Taken together, these data not only indicate that 210 KLF2 and MYC are among the most differentially regulated genes and pathways after HIV infection, but also that their loss of function is sufficient to induce and prevent HIV latency reversal, respectively, likely through regulation of the balance between the activated and quiescent state in CD4+ T cells. 
scRNA-seq demonstrates that activation of KLF2 and p53 pathways is associated with proviral transcriptional shutdown

We also performed single cell RNA-seq analysis on primary CD4+ T cells before infection, 96 hpi with our HIV reporter virus, and following 14 days of incubation of the infected cells in the quiescence-inducing media. As with bulk RNA-seq results (Fig. 1B), dimensionality reduction studies indicated that +HIV 96 hpi cells that were maintained in proliferative media were distinct from the identically maintained uninfected cells and occupied a position between the uninfected and quiescent cells (Fig. 4A). Multiple markers of proliferation and metabolic activation were negatively enriched in the +HIV quiescent and 96 hpi cells compared to proliferative uninfected and +HIV $\alpha$ TCR 24h cells (Extended Data Fig. 9A-D). Analysis of the HIV expression level in +HIV 96 hpi cells indicated that those with a signature of MYC expression had the highest level of expression of the HIV provirus

225 (MYC+ cells, Fig. 4C,D). These cells also had the highest UMI count per cell, consistent with a more activated phenotype (Extended Data Fig. 9E). Cells expressing p53 activation markers in the absence of KLF2 expression had a lower number of cellular RNAs consistent with a more quiescent phenotype, but only a modestly reduced HIV expression level, indicating that induction of p53 signaling per se is not sufficient to transcriptionally silence the provirus (KLF2-p53+ cells, Fig. 4C, D, Extended Data Fig. 230 9E). In contrast, KLF2 expressing cells, even in the absence of p53 signaling, had a much lower number of RNAs per cells and limited the proviral transcription to a basal level (KLF2+p53- cells, Fig. 4C, D, Extended Data Fig. 9E). Importantly, cells in which both KLF2 and the p53 signaling were activated showed a strong reduction of HIV proviral transcriptional activity, with an average of $>75 \%$ reduction in proviral transcription compared to MYC+ cells (KLF2+p53+ cells, Fig. 4C, D, Extended

235 Data Fig. 9E). This strongly reduced proviral transcription level in KLF2+p53+ cells was observed both before and after normalization of proviral expression level to total cellular counts (Extended Data Fig. 9F). Thus, the post-infection concurrent activation of KLF2 and p53 pathways, in addition to reprogramming of cells for entry into quiescence, also sharply reduced the expression of proviral genes, setting the stage for proviral latency and formation of the latent reservoir.

Taken together, our data indicate that HIV infection leads to activation of a multi-pronged mechanism involving KLF2 and p53 pathways that leads to suppression of expression of MYC, which is known to play a pivotal role in maintaining the activated state of $T$ cells ${ }^{53}$. It has been shown that shortly after HIV infection, induction of the IFN response and cellular stress result in p53 activation ${ }^{54,55}$. In addition to its pro-quiescent function, p53 can directly restrict HIV replication and pro-viral gene 245 expression through multiple mechanisms ${ }^{56-59}$, which may contribute to the observed proviral transcriptional shutdown. While the induction of p53 leads to apoptosis in a fraction of HIV infected 
cells $^{60}$, a steep rise in the expression of pro-quiescence, pro-survival factor KLF2 after HIV infection leads to survival and induction of quiescence in CD4+ T cells ${ }^{20,21,24}$. In contrast to $p 53$, the mechanism of induction of KLF2 after HIV infection is not known, and the absence of KLF2 upregulation after

250 treatment of primary CD4+ T cells with IFN- $\alpha$ did not support the possibility that similar to p53, upregulation of KLF2 is induced by the innate immune response (Extended Data Fig. 10A). FOXO1, a critical factor in homeostasis of CD4+ T cells, has been shown to play a role in induction of KLF2 ${ }^{61}$. It is plausible that cellular stress and/or DNA damage response following viral integration leads to activation of FOXO1 ${ }^{62,63}$, which in turn induces the expression of KLF2. Our observation that proviral

255 integration is necessary for KLF2 induction after HIV infection is consistent with this possibility. However, additional signals from the expressed proviral genes are needed for the induction of KLF2 and the quiescence phenotype, as cells transfected with an empty lentiviral vector did not show a rise in KLF2 level compared to control.

Together, the above data reveal a new, previously unknown facet of the formation of the latent

260 reservoir, in which the induction of the major pro-quiescence KLF2 and p53 signaling pathways occurs shortly after infection with HIV, resulting in cellular quiescence and proviral transcriptional shutdown at least in a subset of the infected cells. Accumulating evidence from our work and others ${ }^{4,6-}$ ${ }^{8}$ documents the close association of entry into quiescence with proviral latency. Our observation of pro-quiescence reprogramming of CD4+ T cells shortly after HIV infection suggest that the formation

265 of a population of latently infected cells is an inherent outcome of HIV infection, pointing to the inexorability of the formation of the latent reservoir.

\section{Methods}

For a description of reagents used in this work, please see Supplementary Table 3.

270 Primary cell culture

Peripheral blood mononuclear cells from HIV negative Caucasian male donors were purchased from Allcells. Naive CD4+ T cells were isolated using EasySep ${ }^{\mathrm{TM}}$ Human Naïve CD4+ T Cell Isolation Kit II according to the manufacturer's instructions. Cells were resuspended at $1 \times 10^{6} \mathrm{cells} / \mathrm{ml}$ in primary culture media (RPMI with Normocin, 10\% fetal bovine serum and 25mM HEPES). Immediately after

275 isolation, cells were treated with Dynabeads ${ }^{\mathrm{TM}}$ Human T-Activator CD3/CD28 at a 1:1 bead to cell ratio and $60 \mathrm{IU} / \mathrm{ml} \mathrm{IL-2}$. Cells were maintained at $37^{\circ} \mathrm{C}$ and $5 \% \mathrm{CO}_{2}$. Dynabeads ${ }^{\mathrm{TM}}$ were removed using a magnet after 24 hours. Polarizations into the four major effector T cell subsets Th1, Th2, Th17 
and Treg cells were performed as previously described ${ }^{8}$. During subsequent expansion, cell populations were diluted back to $1 \times 10^{6} \mathrm{cells} / \mathrm{ml}$ in primary culture media and supplemented with an 280 additional $60 \mathrm{IU} / \mathrm{ml} \mathrm{IL}-2$ every two days.

\section{Cell lines}

Jurkat cells were purchased from ATCC and maintained at $37^{\circ} \mathrm{C}$ and $5 \% \mathrm{CO}_{2}$ in the described primary culture medium.

\section{Reporter virus}

285 Single-round VSV-pseudotyped HIV reporter virus included the tat, rev, env, vpu and nef genes and a CD8-EGFP fusion protein that permits the use of magnetic beads for a gentle, minimally-disturbing purification of infected cells (Extended Data Fig. 1A). The viral preparation was performed as previously described ${ }^{8}$.

\section{Reporter virus infection}

290 Ten million polarized CD4+ T cells at a concentration of $5 \times 10^{6} \mathrm{cell} / \mathrm{ml}$ were mixed with high titer singleround VSV-pseudotyped HIV reporter virus and centrifuged at 3,000 rpm for 1.5 hours to promote viral fusion. Cells were incubated overnight in the existing media, then diluted back to $1 \times 10^{6}$ cells $/ \mathrm{ml}$ in primary culture media and supplemented with an additional $60 \mathrm{IU} / \mathrm{ml} \mathrm{IL}-2.72$ hours post reactivation, the infected cells were purified in a minimally disturbing manner using magnetic beads. The purified cells were $>95 \%$ positive for the viral Nef protein and GFP.

\section{Quiescence and reactivation of CD4+ $T$ cells}

To induce quiescence, on day 7 post infection, the purified, HIV-infected (+HIV) or identically maintained uninfected or vector-infected cells were switched to media containing a defined cocktail of

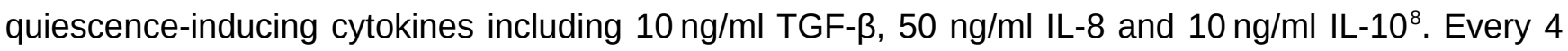

300 days, these cytokines were re-added along with $3.75 \mathrm{IU} / \mathrm{ml} \mathrm{IL}-2$ to maintain cell viability. To reactivate the quiescent cells, they were stimulated through the TCR using CD3/CD28 beads for 24 hours as described above.

Entry into quiescence is confirmed by flow cytometry assays measuring the progressive reduction in proliferation markers and sharply reduced proliferation rate ${ }^{8}$. Once quiescent, the level of HIV expression is reduced to almost undetectable levels (1\%), indicative of HIV latency. Upon stimulation through the TCR by exposure to $\alpha-C D 3 / \alpha-C D 28$ mAbs, the fraction of HIV expressing cells increases dramatically (>80\%), indicative of exit from quiescence and proviral latency. 
$R T-q P C R$ assays

For RT-qPCR-based assays, total cellular RNA was harvested using TRIzol reagent and preparation of

310 cDNA was performed with PrimeScript RT Reagent Kit as described, using both oligo(dT) and random hexamers ${ }^{64}$. The resulting cDNA was used in $\mathrm{qPCR}$ reactions with $\mathrm{iQ}^{\mathrm{TM}}$ SYBR ${ }^{\circledR}$ Green Supermix on an Eppendorf Mastercycler Realplex ${ }^{2}$ system and analyzed as described ${ }^{64}$. For studies with Raltegravir, either vehicle or Raltegravir were added to the proliferating primary CD4+ T cells at a final concentration of $5 \mathrm{mM} 48$ hours before infection with the vector or HIV reporter viral preparations,

315 followed by harvesting the cellular RNA at the indicated time points after infection.

\section{Bulk RNA-seq library preparation}

Preparation of sequencing libraries for bulk RNA-seq studies were performed as previously described $^{8}$. Three replicate experiments were performed over a period of two years. Briefly, poly $(A)+$ RNAs (replicates 1 and 2) or total cellular RNA (replicate 3) was harvested from a million viable Th1,

320 Th2, Th17 and Treg cells 72 hours after infection with the HIV construct shown in Extended Data Fig. 1A containing a GFP-CD8a fusion reporter gene. For total cellular RNA preparations, ribosomal RNAs and other abundant housekeeping RNAs were removed followed by fragmentation, cDNA synthesis and adaptor ligation as previously described ${ }^{8}$. High-throughput sequencing was performed on an Illumina HiSeq2000 instrument.

\section{5 scRNA-seq}

Aliquots of approximately 300,000 cells were taken for scRNA-seq analysis at each of the following time points: before the infection with HIV reporter viruses (Uninfected), 96 hours after infection (+HIV $96 \mathrm{hpi}$ ), fourteen days after the initial quiescence inducing cytokine treatment (+HIV quiescent) and 24 hours after reactivation using CD3/CD28 beads (+HIV aTCR 24h). The Drop-seq protocol was

330 performed according to the McCarrol laboratory guidebook ${ }^{65}$. Barcoded mRNA capture beads were used at a concentration of 120,000 beads $/ \mathrm{ml}$ in lysis buffer prepared as described. Cells were used at 100 cells/ $\mu \mathrm{l}$ in PBS/10\% Bovine Serum Albumin. Flow rates were set to 2,000 $\mu \mathrm{l} / \mathrm{hr}$ for cells and beads and $7,500 \mu \mathrm{l} / \mathrm{h}$ for oil. The beads were then washed with 6x SSC and the 5x RT buffer supplied with Maxima $\mathrm{H}$ minus reverse transcriptase. Reverse transcription, treatment with Exonuclease I, PCR

335 amplifications and tagmentation were performed strictly as described in the Drop-seq guidebook ${ }^{65}$ using Maxima $\mathrm{H}$ minus reverse transcriptase, Exonuclease I and Nextera XT DNA Library Preparation Kit. Next Generation Sequencing (NGS) of the DNA libraries were performed using the Illumina HiSeq $X$ at Medgenome, Inc. 
Defining the quiescence-related gene signatures

340 To identify genes that change in a concordant manner during quiescence in different cell types capable of entry into a quiescent state we selected quiescence-related pathways in the mSigDB which had been derived from non-cancerous cells, along with a related published study (accession number: GSE24739) on quiescence in primary hematopoietic stem cells ${ }^{28}$. The resulting gene list was used as a signature of gene expression pattern in quiescent cells and was compared to the datasets analyzed

345 in this study.

shRNA screen

The shRNA screen using Cellecta shRNA library was performed as previously described ${ }^{51}$. Briefly, Jurkat T cells harboring a latent GFP reporter-containing HIV provirus (E4 cells) were infected with the shRNA library and GFP+ cells were screened for constitutive activation of the latent provirus through a

350 sequencing-based approach. This approach identified genes that when knocked down, resulted in T cell reactivation and/or HIV proviral activation. A reverse screen was performed in which cells were stimulated with TCR agonists, resulting in enhanced proliferation of Jurkat cells and reactivation of the latent provirus. Cells which did not reactivate the provirus were selected to identify the genes for which knock down resulted in a block to $T$ cell proliferation and/or proviral reactivation. The combined results

355 of the dual screen were matched against the genes showing concordant expression among all early time point HIV infection RNA-seq datasets and the resulting list of genes was evaluated for positive or negative enrichment.

\section{Flow cytometry analysis}

Cells were washed with PBS and treated with Fixable Viability Dye eFluor ${ }^{\mathrm{TM}} 450$ for 15 minutes, then 360 washed with PBS again. Cells were fixed in 4\% formaldehyde and permeabilized with Perm/Wash ${ }^{\mathrm{TM}}$ buffer. To detect Cyclin D3 and Ki67, cells were incubated with $3 \mu \mathrm{g} / \mathrm{ml}$ AF647 mouse anti-Ki67 and 3 $\mu \mathrm{g} / \mathrm{ml}$ PE mouse anti-Cyclin D3 for 15 minutes. Perm/Wash ${ }^{\mathrm{TM}}$ buffer was used to wash the cells twice after incubations. Fluorescent signals were measured using a BD LSRFortessa ${ }^{\mathrm{TM}}$ Flow Cytometer.

\section{Analysis of cellular proliferation}

365 To assess proliferation of RITA and vehicle treated cell populations, viable cell count was measured at the same time each day using trypan blue stain and a Countess ${ }^{\mathrm{TM}}$ II FL Automated Cell Counter.

RITA, simvastatin and Nutlin treatments

To upregulate p53, cells were treated with the small-molecule MDM2 inhibitors RITA and Nutlin. RITA 13 
was used at a concentration of $10 \mu \mathrm{M}$ for Th17 cells (Fig. 3A,D) or $1.5 \mu \mathrm{M}$ for unpolarized CD4+ T 370 cells which were more susceptible to RITA toxicity (Fig. 3B,C). Nutlin was used at $10 \mu \mathrm{M}$ concentration. To upregulate KLF2, cells were treated with $10 \mu \mathrm{M}$ Simvastatin. As a control for each drug treatment, a parallel population was treated with an equivalent volume of DMSO, the vehicle used for drug delivery.

\section{Knock down studies of MYC and KLF2}

375 One million cells were washed with PBS and resuspended in $60 \mu \mathrm{l}$ MaxCyte electroporation buffer. Dicer-substrate short interfering RNAs (dsiRNAs) targeting MYC, KLF2 or a scrambled sequence were added at $3 \mu \mathrm{M}$ concentration. For MYC and KLF2, two different dsiRNA constructs were used as a mixture. A TEX615-labeled non-targeting dsiRNA was applied at the same concentration as a transfection efficiency control. Electroporation was performed using the MaxCyte STX® Scalable

380 Transfection System. Cells were incubated at $37^{\circ} \mathrm{C}$ for 15 mins in the existing buffer, then resuspended at $1 \times 10^{6} \mathrm{cells} / \mathrm{ml}$ in primary culture media with $60 \mathrm{IU} / \mathrm{ml} \mathrm{IL}-2$ or the quiescence inducing cytokine cocktail described above. Fluorescent signal from transfection efficiency control dsiRNA was detected using a BD LSRFortessa ${ }^{\mathrm{TM}}$ Flow Cytometer.

\section{Immunofluorescence cytochemistry assays}

385 For immunofluorescent detection of p53 following RITA treatment, 200,000 cells were fixed in $4 \%$ formaldehyde at 8 hours post-treatment, then permeabilized with Perm/Wash ${ }^{\mathrm{TM}}$ buffer. To detect p53, cells were incubated with rabbit anti-p53 primary antibody at $7 \mu \mathrm{g} / \mathrm{ml}$, then AF647 goat anti-rabbit secondary antibody at $7 \mu \mathrm{g} / \mathrm{ml}$ for 15 minutes each. DAPI was also applied at $1 \mu \mathrm{M}$ concentration for 5 minutes. Perm/Wash ${ }^{\mathrm{TM}}$ buffer was used to wash the cells twice after each incubation. Cells were 390 transferred to $0.17 \mathrm{~mm}$ poly-L lysine coated cover slips and mounted onto microscope slides with ProLong ${ }^{\mathrm{TM}}$ Diamond Antifade Mountant. Images were collected using a DeltaVision Deconvolution Microscope.

\section{Quantification and Statistical Analysis}

395 All experiments were performed with at least three technical replicates and two or more biological replicates. All error bars shown in figures correspond to standard error of the mean (SEM).

\section{RT-qPCR data analysis}

At least two technical repeats and two biological repeats were performed for each RT-qPCR 
experiment. Error bars represent the standard error of the mean (SEM). To determine the statistical

400 significance of observed differences, $p$-values were calculated using Student's t-test with $p$-values $<0.05$ considered significant.

\section{Analysis of bulk RNA-seq data}

An average of $\sim 50$ million single end (replicates 1 and 2) or paired-end reads (replicate 3) were obtained for each sample. RNA-seq reads were quality controlled using Fastqc and trimmed for any

405 leftover adaptor-derived sequences, and sequences with Phred score less than 30 with Trim Galore, which is a wrapper based on Cutadapt and FastQC. Any reads shorter than 40 nucleotides after the trimming were not used in alignment. The pre-processed reads were aligned to the human genome (hg38/GRCh38) with the Gencode release 27 as the reference annotations using STAR version 2.7.2b ${ }^{66}$, followed by gene-level quantitation using htseq-count ${ }^{67}$. In parallel, the pre-processed reads were

410 pseudoaligned using Kallisto version $0.43 .1^{68}$ with 100 rounds of bootstrapping to the Gencode release 27 of the human transcriptome to which the sequence of the transfected HIV genome and the deduced HIV spliced transcripts were added. The resulting quantitations were normalized using Sleuth. The two pipelines yielded concordant results. Pairwise differential expression tests were performed using edgeR $(\mathrm{QL})^{69}$ and false discovery rate (FDR) values were calculated for each

415 differential expression value.

Protein-coding genes that were expressed at a minimum abundance of 5 transcripts per million (TPM) were used for pathway analysis with fold change values as the ranking parameter while controlling false discovery rate at 0.05 . Gene Set Enrichment Analysis (GSEA) package was used to identify the enriched pathway and promoter elements using datasets C2, C3, C5 and Hallmark in the mSigDB.

420 Pathways that showed an FDR q-value <= 0.25 were considered significantly enriched, per the GSEA package guidelines. The number of genes contributing the enrichment score was calculated using the leading edge output of GSEA (tag multiplied by size).

Publicly available datasets focusing on early time points after HIV infection were analyzed as described above and the results were compared to the published manuscript associated with the 425 dataset, when applicable, which showed complete agreement between our analysis and the results reported in the related manuscripts. Datasets that showed $>50 \%$ infection rate were included in the study in an effort to capture the transcriptomic pattern of the infected, rather than bystander, cells. Genes which showed concordant differential expression in all datasets were selected and the average of differential expression values was used to identify the top shared differentially expressed genes.

\section{Analysis of scRNA-seq data}


Genomic alignment was performed using kallisto-BUS ${ }^{70}$ followed by analysis using Scanpy ${ }^{71}$. A total of 24,894 cells were used in the final analysis with at least 100 genes detected in each cell. To determine the expression level of key factors involved in regulation of the quiescence program, the expression level of HIV provirus was calculated, along with the expression of KLF2, MYC, and factors that

435 comprised the signature of p53 and MYC activation. As MYC mRNA has one of the shortest known half-lives for an mRNA, the expression of MYC and its downstream transcriptional targets including MKI67/ki67, TFRC/CD71, and CCND3/cyclin D3 and IL2RA/CD25 were used in conjunction with MYC RNA itself to identify cells showing the signature of MYC activity (MYC+ cells), defined as cells showing the expression of any two of the above factors. For defining the signature of p53 activation in

440 early time points after HIV infection, the p53 gene list from the curated Hallmark database of mSigDB was used. Genes included in the "negative regulation of p53" in the GO database were removed from the list, and intersected with the list of genes induced after HIV infection in at least four of the datasets in Table S1. The resulting list of genes (TOB1, CDKN1A, BBC3, S100A10, HINT1, EEF2, LDHB, BTG1, IP6K2) were used for identifying the cells carrying the signature of p53 activation (p53+ cells),

445 defined as cells showing the expression of any two of the above-listed factors. Analysis of the genes directly involved in the p53-mediated induction of apoptosis indicated that they were almost entirely absent from the p53+ cells. Cells that showed the expression of both MYC and KLF2 (2 cells) signature, or MYC and p53 signature genes as detailed above, were eliminated from the analysis. Those showing the expression of both KLF2 and p53 signature genes were placed in the KLF2+p53+

450 category. Studies performed before and after normalization of gene expression values to total cellular counts (UMIs) yielded highly similar results. The results obtained using raw reads, which are more pertinent to the study of proviral quiescence, were used to generate the Figures reported in this study.

\section{MYC knock down transcriptomic studies}

Analysis of the publicly available MYC knockdown datasets (Table S2) were performed as described

455 above. Protein-coding genes showing a differential expression $>1.5$ fold with FDR $<0.05$ were used to identify enriched pathways using the MSigDB hallmark version 6.2 gene set using GSEA 4.0.0. A false discovery rate of 0.25 was used as a cutoff to determine statistically significant enriched pathways per GSEA guidelines.

\section{Acknowledgments}

We thank Uri Mbonye and Kien Nguyen for providing reagents, discussions and insights. This work made use of the Genomics Core Facility, the High Performance Computing Resource for Advanced 16 
Research Computing and flow cytometry and virology cores of the Center for AIDS Research (CFAR) at Case Western Reserve University. This work was supported by T32AI127201-4 to L.P., R21-

465 Al127252 and two Development Awards from CFAR P30-AI36219 to S.V., and R01-AI120204, R01Al148083 and P30-Al36219 to J.K.

\section{Author Contributions}

S.V. and J.K. conceived of and oversaw the study. S.V. and F.N. performed the computational studies except as noted. L.P. and L.S.G. performed the non-computational studies except as noted. S.M. 470 performed studies in Extended Data Fig. 7A-C. K.L. and W.S.N performed the single cell RNA-seq. G.P. performed studies in Fig. 2E. C.D. performed bulk RNA-seq library preparation and together with L.P., studies in Fig. 2F, 3H, I. M.S. prepared primary cell models needed for this study and performed studies in Fig. 2B, Extended Data Fig. 4G, and along with L.P., 2C. S.V. and J.K. wrote the manuscript, S.V. and L.P. prepared the Figures and Methods section. S.V. submitted the RNA-seq studies 475 performed in this project to SRA (accession number SRP145508).

\section{Declaration of Interests}

The authors declare no competing interests. 


\section{References}

1. Dutilleul, A., Rodari, A. \& Van Lint, C. Depicting HIV-1 Transcriptional Mechanisms: A Summary of What We Know. Viruses 12, 1385 (2020).

2. Orenstein, J. M. et al. Rapid activation of lymph nodes and mononuclear cell HIV expression upon interrupting highly active antiretroviral therapy in patients after prolonged viral suppression. AIDS 14, 1709-1715 (2000).

3. Shen, L. \& Siliciano, R. F. Viral reservoirs, residual viremia, and the potential of highly active antiretroviral therapy to eradicate HIV infection. J. Allergy Clin. Immunol. 122, 22-28 (2008).

4. Agosto, L. M. \& Henderson, A. J. CD4+ T Cell Subsets and Pathways to HIV Latency. AIDS Res. Hum. Retroviruses 34, 780-789 (2018).

5. Mbonye, U. \& Karn, J. The Molecular Basis for Human Immunodeficiency Virus Latency. Annual Review of Virology 4, 261-285 (2017).

6. Shukla, A., Ramirez, N.-G. P. \& D'Orso, I. HIV-1 Proviral Transcription and Latency in the New Era. Viruses 12, 555 (2020).

7. Shan, L. et al. Transcriptional Reprogramming during Effector-to-Memory Transition Renders CD4+ T Cells Permissive for Latent HIV-1 Infection. Immunity 47, 766-775.e3 (2017).

8. Dobrowolski, C. et al. Entry of Polarized Effector Cells into Quiescence Forces HIV Latency. MBio 10, e00337-19 (2019).

9. Siliciano, R. F. \& Greene, W. C. HIV latency. Cold Spring Harb Perspect Med 1, a007096 (2011).

10. Richman, D. D. et al. The challenge of finding a cure for HIV infection. Science 323, 1304-1307 (2009).

11. International AIDS Society Scientific Working Group on HIV Cure et al. Towards an HIV cure: a global scientific strategy. Nat. Rev. Immunol. 12, 607-614 (2012).

12. Pedro, K. D., Henderson, A. J. \& Agosto, L. M. Mechanisms of HIV-1 cell-to-cell transmission and the establishment of the latent reservoir. Virus Res 265, 115-121 (2019).

13. Chavez, L., Calvanese, V. \& Verdin, E. HIV Latency Is Established Directly and Early in Both 
Resting and Activated Primary CD4 T Cells. PLoS Pathog. 11, e1004955 (2015).

14. Lenasi, T., Contreras, X. \& Peterlin, B. M. Transcriptional interference antagonizes proviral gene expression to promote HIV latency. Cell Host Microbe 4, 123-133 (2008).

15. Mori, L. \& Valente, S. T. Key Players in HIV-1 Transcriptional Regulation: Targets for a Functional Cure. Viruses 12, 529 (2020).

16. Morton, E. L. et al. Transcriptional Circuit Fragility Influences HIV Proviral Fate. Cell Rep 27, 154171.e9 (2019).

17. Razooky, B. S., Pai, A., Aull, K., Rouzine, I. M. \& Weinberger, L. S. A Hardwired HIV Latency Program. Cell 160, 990-1001 (2015).

18. Weinberger, L. S., Burnett, J. C., Toettcher, J. E., Arkin, A. P. \& Schaffer, D. V. Stochastic gene expression in a lentiviral positive-feedback loop: HIV-1 Tat fluctuations drive phenotypic diversity. Cell 122, 169-182 (2005).

19. Jha, P. \& Das, H. KLF2 in Regulation of NF-kB-Mediated Immune Cell Function and Inflammation. International Journal of Molecular Sciences 18, 2383 (2017).

20. Buckley, A. F., Kuo, C. T. \& Leiden, J. M. Transcription factor LKLF is sufficient to program T cell quiescence via a c-Myc-dependent pathway. Nat. Immunol. 2, 698-704 (2001).

21. Haaland, R. E., Yu, W. \& Rice, A. P. Identification of LKLF-regulated genes in quiescent CD4+ T lymphocytes. Mol. Immunol. 42, 627-641 (2005).

22. Tzachanis, D. et al. Tob is a negative regulator of activation that is expressed in anergic and quiescent T cells. Nat. Immunol. 2, 1174-1182 (2001).

23. Ho, K. J. et al. Tob1 is a constitutively expressed repressor of liver regeneration. J Exp Med 207, 1197-1208 (2010).

24. Kuo, C. T., Veselits, M. L. \& Leiden, J. M. LKLF: A transcriptional regulator of single-positive T cell quiescence and survival. Science 277, 1986-1990 (1997).

25. Mohammadi, P. et al. Dynamics of HIV Latency and Reactivation in a Primary CD4+ T Cell Model. PLoS Pathog 10, e1004156 (2014).

26. White, C. H. et al. Transcriptomic Analysis Implicates the p53 Signaling Pathway in the 
Establishment of HIV-1 Latency in Central Memory CD4 T Cells in an In Vitro Model. PLoS Pathog. 12, e1006026 (2016).

27. Wang, R. et al. The Transcription Factor Myc Controls Metabolic Reprogramming upon T Lymphocyte Activation. Immunity 35, 871-882 (2011).

28. Affer, M. et al. Gene Expression Differences between Enriched Normal and Chronic Myelogenous Leukemia Quiescent Stem/Progenitor Cells and Correlations with Biological Abnormalities. J Oncol 2011, 798592 (2011).

29. Brennan, P. et al. Phosphatidylinositol 3-kinase couples the interleukin-2 receptor to the cell cycle regulator E2F. Immunity 7, 679-689 (1997).

30. Yao, G. Modelling mammalian cellular quiescence. Interface Focus 4, 20130074 (2014).

31. Peng, X. et al. Deep Sequencing of HIV-Infected Cells: Insights into Nascent Transcription and Host-Directed Therapy. J Virol 88, 8768-8782 (2014).

32. Wang, Q. et al. The p53 Family Coordinates Wnt and Nodal Inputs in Mesendodermal Differentiation of Embryonic Stem Cells. Cell Stem Cell 20, 70-86 (2017).

33. Chang, S. T. et al. Next-generation sequencing reveals HIV-1-mediated suppression of $\mathrm{T}$ cell activation and RNA processing and regulation of noncoding RNA expression in a CD4+ T cell line. MBio 2, e00134-11 (2011).

34. Sherrill-Mix, S., Ocwieja, K. E. \& Bushman, F. D. Gene activity in primary T cells infected with HIV89.6: intron retention and induction of genomic repeats. Retrovirology 12, 79 (2015).

35. Kleinman, C. L. et al. HIV-1 Infection Causes a Down-Regulation of Genes Involved in Ribosome Biogenesis. PLoS One 9, e113908 (2014).

36. Langer, $\mathrm{S}$. et al. HIV-1 $\mathrm{Vpu}$ is a potent transcriptional suppressor of NF-KB-elicited antiviral immune responses. Elife 8, e41930 (2019).

37. Locher, C. P. et al. Differential effects of R5 and X4 human immunodeficiency virus type 1 infection on CD4+ cell proliferation and activation. Journal of General Virology 86, 1171-1179 (2005).

38. Batra, R. et al. RNA-binding protein CPEB1 remodels host and viral RNA landscapes. Nat. 
Struct. Mol. Biol. 23, 1101-1110 (2016).

39. Gupta, A., Brown, C. T., Zheng, Y.-H. \& Adami, C. Differentially-Expressed Pseudogenes in HIV-1 Infection. Viruses 7, 5191-5205 (2015).

40. Ryan, S. K. et al. Neuroinflammation and EIF2 Signaling Persist despite Antiretroviral Treatment in an hiPSC Tri-culture Model of HIV Infection. Stem Cell Reports 14, 703-716 (2020).

41. Leone, G., DeGregori, J., Sears, R., Jakoi, L. \& Nevins, J. R. Myc and Ras collaborate in inducing accumulation of active cyclin E/Cdk2 and E2F. Nature 387, 422-426 (1997).

42. Leone, G. et al. Myc Requires Distinct E2F Activities to Induce S Phase and Apoptosis. Molecular Cell 8, 105-113 (2001).

43. DeRyckere, D. \& DeGregori, J. E2F1 and E2F2 are differentially required for homeostasis-driven and antigen-induced T cell proliferation in vivo. J. Immunol. 175, 647-655 (2005).

44. Murga, M. et al. Mutation of E2F2 in Mice Causes Enhanced T Lymphocyte Proliferation, Leading to the Development of Autoimmunity. Immunity 15, 959-970 (2001).

45. Ho, J. S. L., Ma, W., Mao, D. Y. L. \& Benchimol, S. p53-Dependent Transcriptional Repression of C-myc Is Required for G1 Cell Cycle Arrest. Molecular and Cellular Biology 25, 7423-7431 (2005).

46. Issaeva, N. et al. Small molecule RITA binds to p53, blocks p53-HDM-2 interaction and activates p53 function in tumors. Nat. Med. 10, 1321-1328 (2004).

47. Vassilev, L. T. et al. In Vivo Activation of the p53 Pathway by Small-Molecule Antagonists of MDM2. Science 303, 844-848 (2004).

48. Bu, D. et al. Statin-induced Kruppel-like factor 2 expression in human and mouse $\mathrm{T}$ cells reduces inflammatory and pathogenic responses. J Clin Invest 120, 1961-1970 (2010).

49. Parmar, K. M. et al. Statins exert endothelial atheroprotective effects via the KLF2 transcription factor. J. Biol. Chem. 280, 26714-26719 (2005).

50. Sen-Banerjee, S. et al. Kruppel-like factor 2 as a novel mediator of statin effects in endothelial cells. Circulation 112, 720-726 (2005).

51. Das, B. et al. Estrogen receptor-1 is a key regulator of HIV-1 latency that imparts gender-specific 
restrictions on the latent reservoir. Proc. Natl. Acad. Sci. U.S.A. 115, E7795-E7804 (2018).

52. Pedro, K. D. et al. A functional screen identifies transcriptional networks that regulate HIV-1 and HIV-2. Proc Natl Acad Sci U S A 118, e2012835118 (2021).

53. Muhar, M. et al. SLAM-seq defines direct gene-regulatory functions of the BRD4-MYC axis. Science 360, 800-805 (2018).

54. Imbeault, M., Ouellet, M. \& Tremblay, M. J. Microarray study reveals that HIV-1 induces rapid type-I interferon-dependent p53 mRNA up-regulation in human primary CD4+ T cells. Retrovirology 6, 5 (2009).

55. Takaoka, A. et al. Integration of interferon-alpha/beta signalling to p53 responses in tumour suppression and antiviral defence. Nature 424, 516-523 (2003).

56. Bargonetti, J., Chicas, A., White, D. \& Prives, C. p53 represses Sp1 DNA binding and HIV-LTR directed transcription. Cell. Mol. Biol. (Noisy-le-grand) 43, 935-949 (1997).

57. Li, C. J., Wang, C., Friedman, D. J. \& Pardee, A. B. Reciprocal modulations between p53 and Tat of human immunodeficiency virus type 1. Proc. Natl. Acad. Sci. U.S.A. 92, 5461-5464 (1995).

58. Shi, B. et al. Inhibition of HIV early replication by the p53 and its downstream gene p21. Virol J 15, 53 (2018).

59. Yoon, C.-H. et al. p53-derived host restriction of HIV-1 replication by protein kinase R-mediated Tat phosphorylation and inactivation. J. Virol. 89, 4262-4280 (2015).

60. Genini, D. et al. HIV induces lymphocyte apoptosis by a p53-initiated, mitochondrial-mediated mechanism. FASEB J. 15, 5-6 (2001).

61. Kerdiles, Y. M. et al. Foxo1 links homing and survival of naive T cells by regulating L-selectin, CCR7 and interleukin 7 receptor. Nat Immunol 10, 176-184 (2009).

62. Huang, H., Regan, K. M., Lou, Z., Chen, J. \& Tindall, D. J. CDK2-Dependent Phosphorylation of FOXO1 as an Apoptotic Response to DNA Damage. Science 314, 294-297 (2006).

63. Eijkelenboom, A. \& Burgering, B. M. T. FOXOs: signalling integrators for homeostasis maintenance. Nat. Rev. Mol. Cell Biol. 14, 83-97 (2013).

64. Zhang, B. et al. A Novel RNA Motif Mediates the Strict Nuclear Localization of a Long Noncoding 
RNA. Mol. Cell. Biol. 34, 2318-2329 (2014).

65. Macosko, E. Z. et al. Highly Parallel Genome-wide Expression Profiling of Individual Cells Using Nanoliter Droplets. Cell 161, 1202-1214 (2015).

66. Dobin, A. \& Gingeras, T. R. Mapping RNA-seq Reads with STAR. Curr Protoc Bioinformatics 51, 11.14.1-11.14.19 (2015).

67. Anders, S., Pyl, P. T. \& Huber, W. HTSeq-a Python framework to work with high-throughput sequencing data. Bioinformatics 31, 166-169 (2015).

68. Bray, N. L., Pimentel, H., Melsted, P. \& Pachter, L. Near-optimal probabilistic RNA-seq quantification. Nat. Biotechnol. 34, 525-527 (2016).

69. Robinson, M. D., McCarthy, D. J. \& Smyth, G. K. edgeR: a Bioconductor package for differential expression analysis of digital gene expression data. Bioinformatics 26, 139-140 (2010).

70. Melsted, P., Ntranos, V. \& Pachter, L. The barcode, UMI, set format and BUStools. Bioinformatics 35, 4472-4473 (2019).

71. Wolf, F. A., Angerer, P. \& Theis, F. J. SCANPY: large-scale single-cell gene expression data analysis. Genome Biol. 19, 15 (2018). 
A

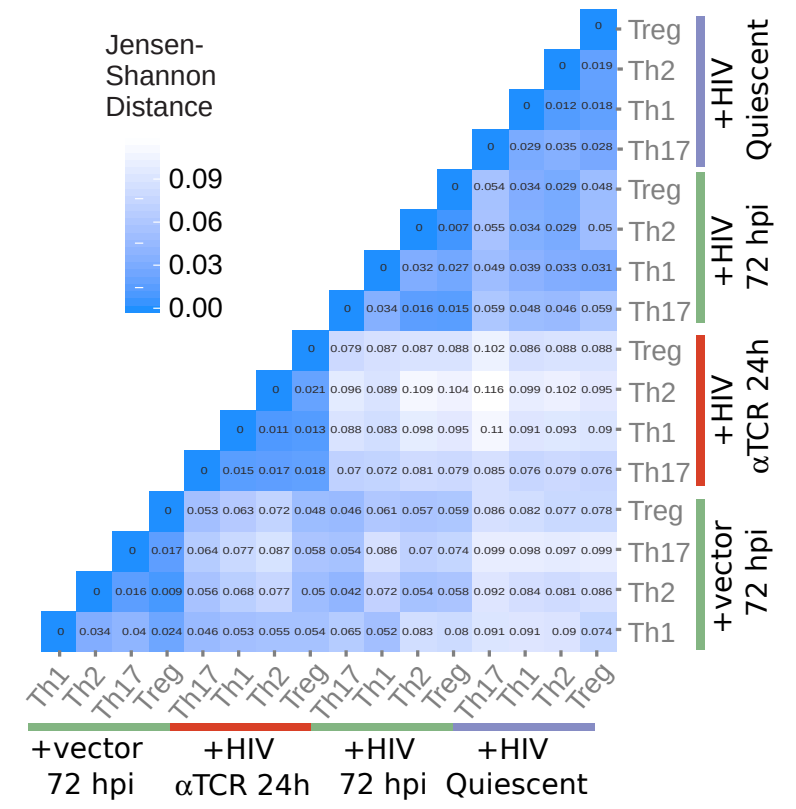

C

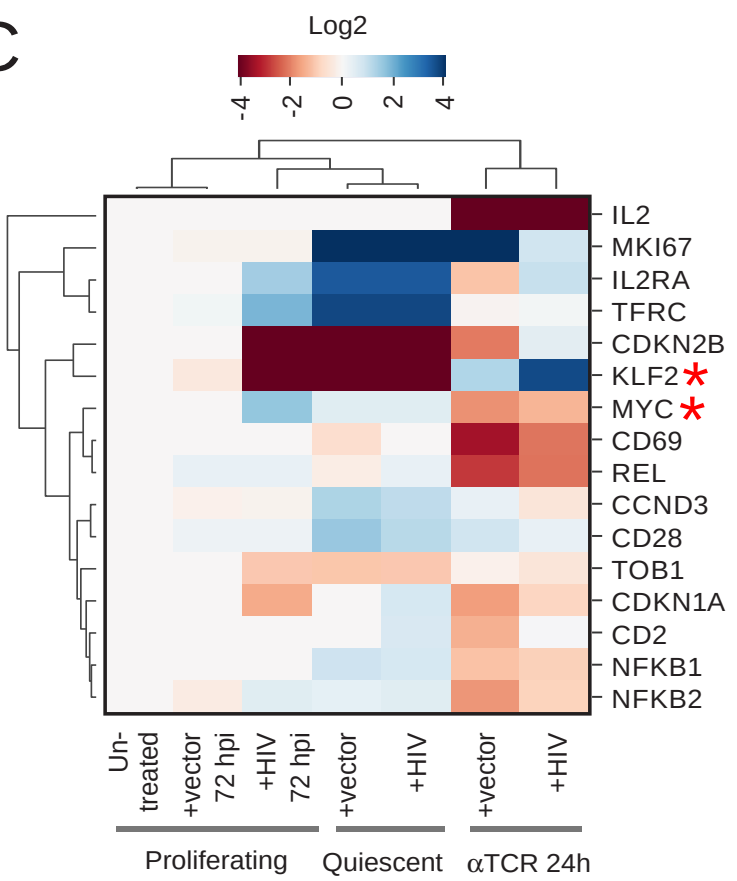

B

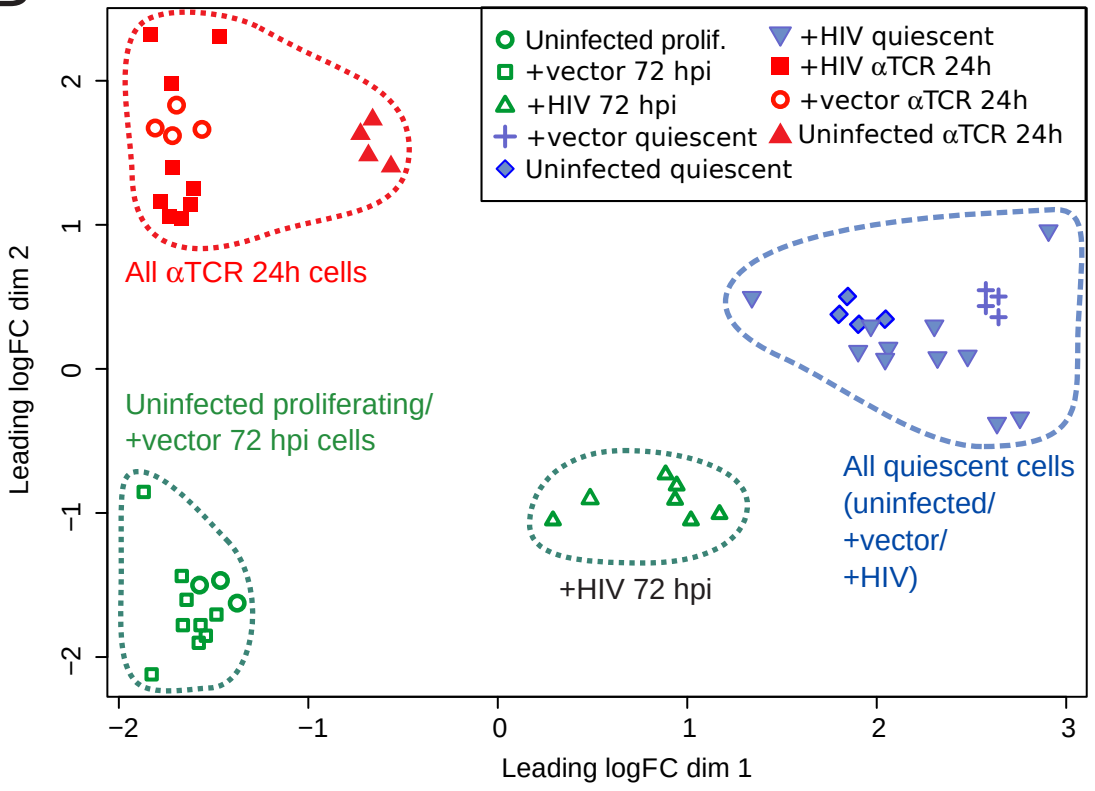

D permatogenesis (26) Mitotic spindle (55) MTORC1 signaling (140) MYC targets v1 (154) Oxidative phosphorylation (154) Estrogen response late (39) Cholesterol homeostasis (36) Glycolysis (66) DNA repair (82) MYC targets v2 (39) Hypoxia (56)

UV response up (68) Fatty acid metabolism (85) IL2 STAT5 signaling (44) PI3K AKT MTOR signaling (50) Unfolded protein response (72) Wnt beta catenin signaling (5) KRAS signaling down (25) Epithelial mesenchymal transition (25)

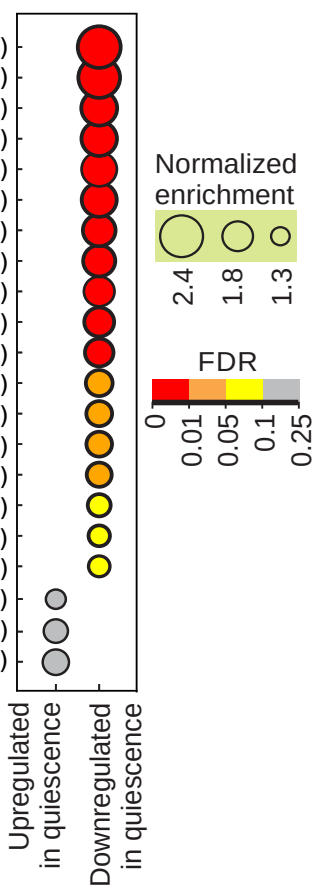

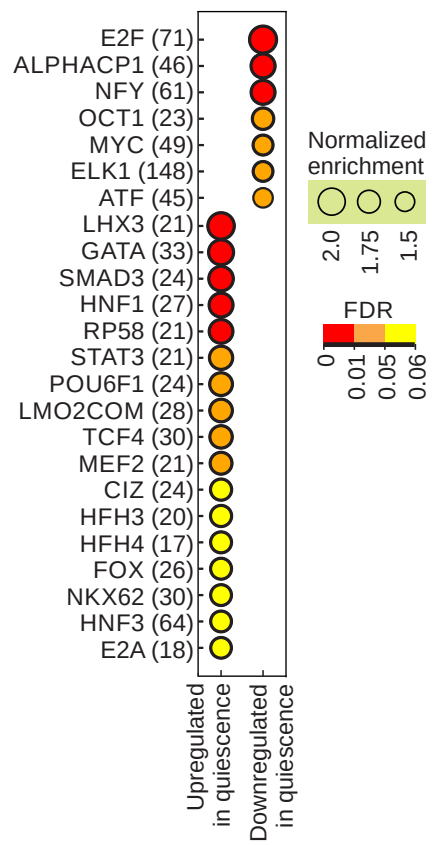


Figure 1. HIV infection, entry and exit from quiescence are accompanied by strong changes in overall gene expression patterns.

A. Jensen-Shannon distance analysis of the overall transcriptomic pattern of the four polarized QUECEL ex vivo models at each step of the HIV life cycle indicates strong similarities between polarized cells. B. Dimensionality reduction study using multi-dimensional scaling indicating the presence of strong transcriptomic changes in early time points following HIV infection. C. Expression of markers of quiescent and proliferative states at different stages of HIV and T cell life cycle. D. Several pathways and gene sets from the Hallmark database of mSigDB were significantly positively and negatively enriched during transition of vector-infected and uninfected cells from proliferating to quiescence state. Numbers between parentheses indicate the number of genes in each pathway that drive the enrichment phenotype (see Materials and Methods). E. The activity of multiple transcription factors show strong changes after entry into quiescence in uninfected and +vector primary CD4+ T cells. 
A

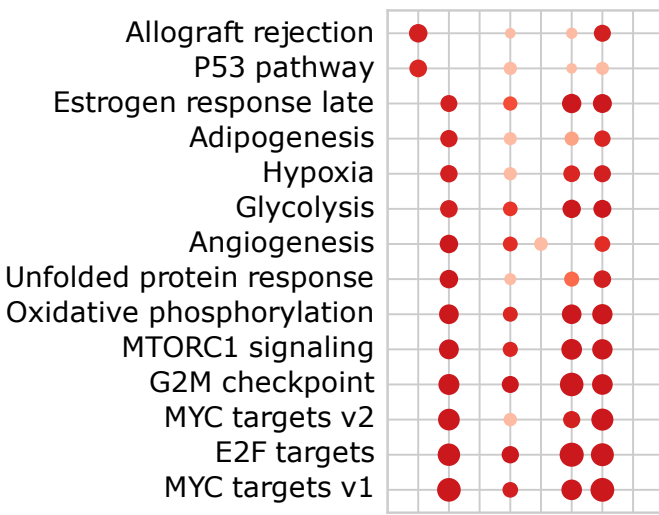

FDR

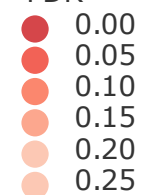

Normalized enrichment

\begin{tabular}{ll}
- & 1.2 \\
\hdashline & 1.5 \\
$\bigcirc$ & 1.8 \\
$\bigcirc$ & 2.1 \\
\hline & 2.4
\end{tabular}

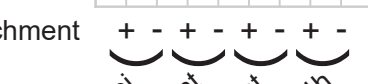

\section{C}

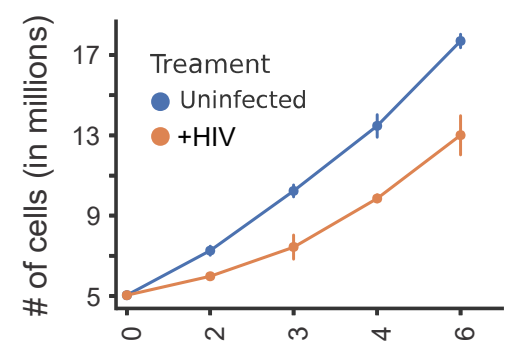

Days after HIV/mock infection

B Day 0: prior to infection

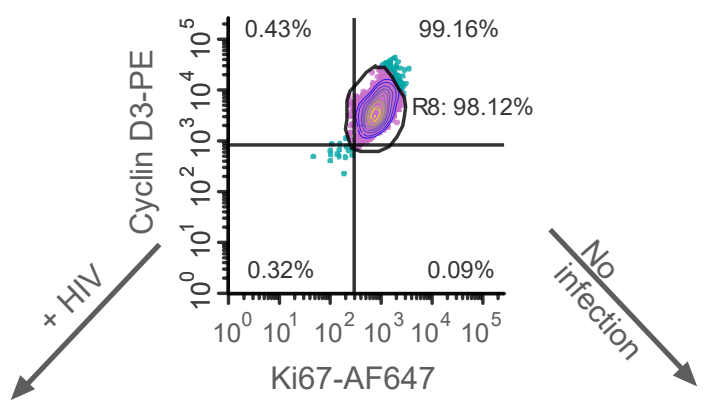

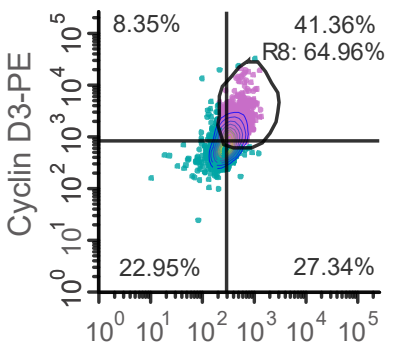

Ki67-AF647

Day 2 ம엉 $0.35 \%$ 98.96\%

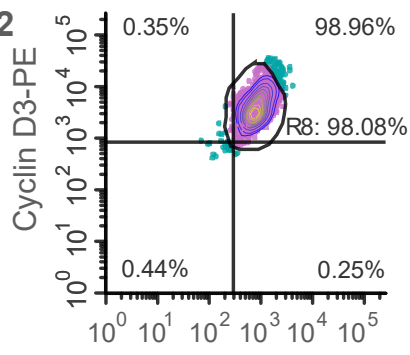

Ki67-AF647

Day 4

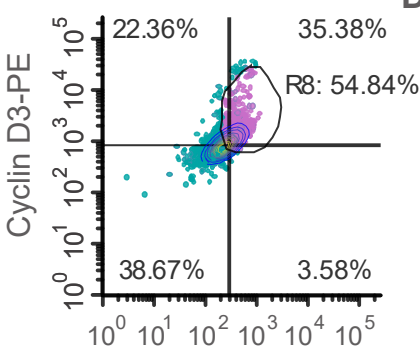

Ki67-AF647

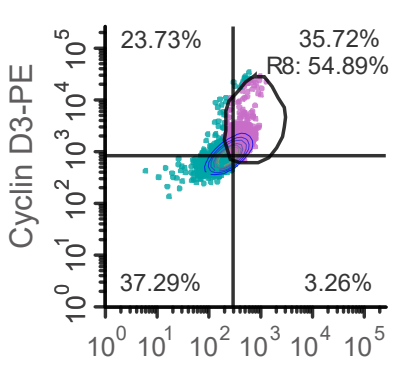

Ki67-AF647

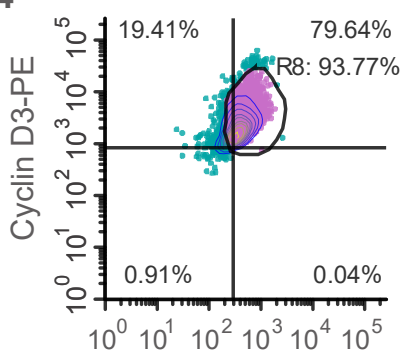

Ki67-AF647

Day 6

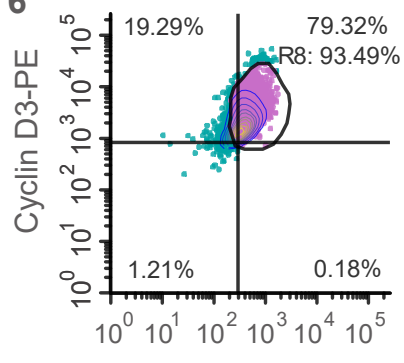

Ki67-AF647

Fig. 2 
Figure 2. HIV infection leads to strong downregulation of the key proliferation factor MYC and decrease in cellular proliferation processes.

A. Several proliferative Hallmark pathways and gene sets are negatively enriched 72 hours following HIV infection. For comparison, pathways changing in +vector cells during entry into and exit from the quiescence state are shown, along with those changing during the transition of $+\mathrm{HIV} 72$ hpi cells to full quiescence. For this and panels $D$ and $E$, plus and minus signs at the bottom indicate positive or negative enrichment, respectively. B. Flow cytometry analysis of unpurified, minimally disturbed HIV infected and identically treated uninfected cells after 2, 4 and 6 days of infection or mock infection indicates the reduction of proliferation markers in HIV infected cells. C. HIV infection leads to a slowdown of cellular proliferation. Uninfected and HIV infected cells were grown in proliferative media in the presence of IL-2 and IL-7 and cell numbers for each group were counted at 2, 3, 4 and 6 days after infection or mock infection. D. Targets of proliferative transcription factors including MYC and E2F1 are negatively enriched 72 hours after HIV infection. For comparison, changes in transcription factor activity during entry into and exit from quiescence in +vector cells are shown. E. Knock down of MYC results in a transcriptomic profile closely similar to quiescence in CD4+ T cells. Comparison of pathway analysis profile of quiescent T cells (leftmost sample) and four independently performed MYC knockdown studies (including a study in lymphocytes) point to strong similarities including negative enrichment of key proliferative pathways. F. Knock down of MYC using siRNAs (siMYC) results in strong loss of expression of cyclins D3 and B1 compared to cells treated with a non-targeting siRNA. Both control and knock down cells were incubated in proliferative media containing high levels of IL-2. 


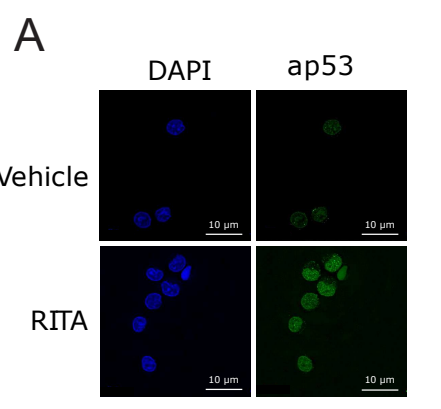

B

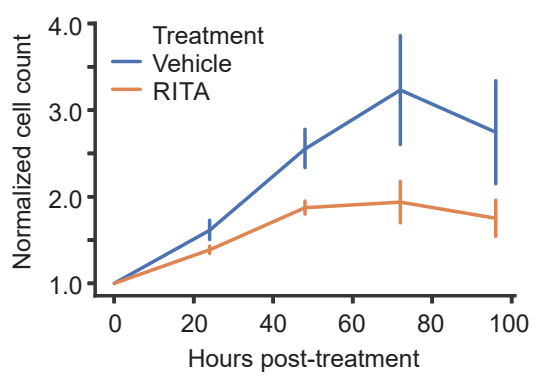

D

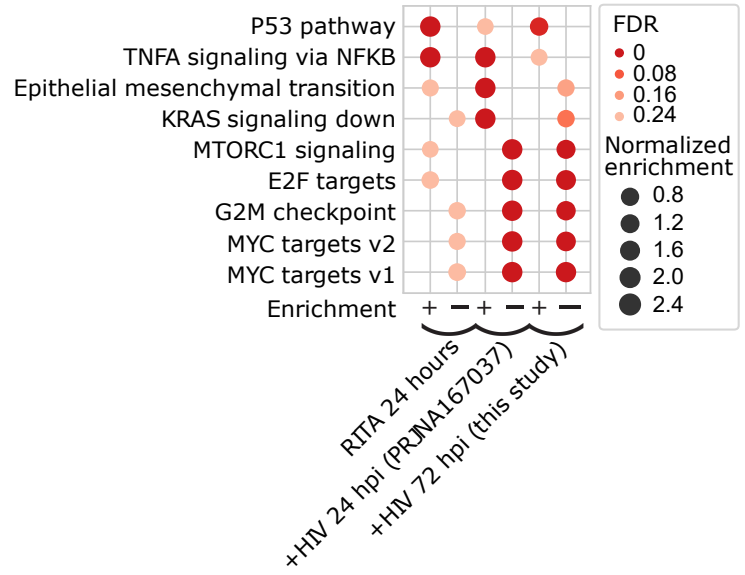

E
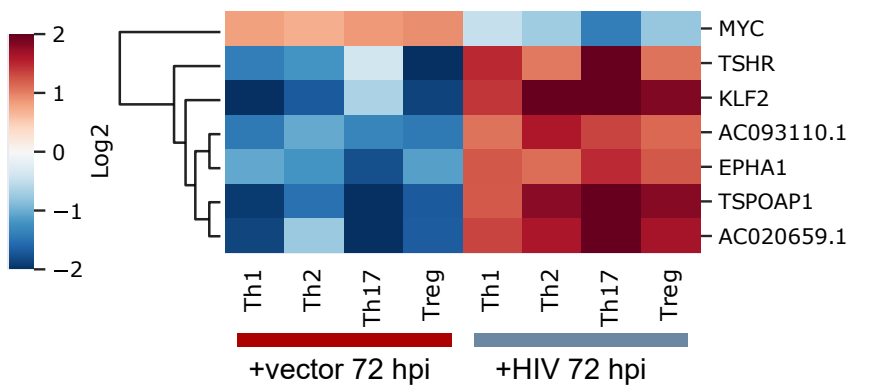

G

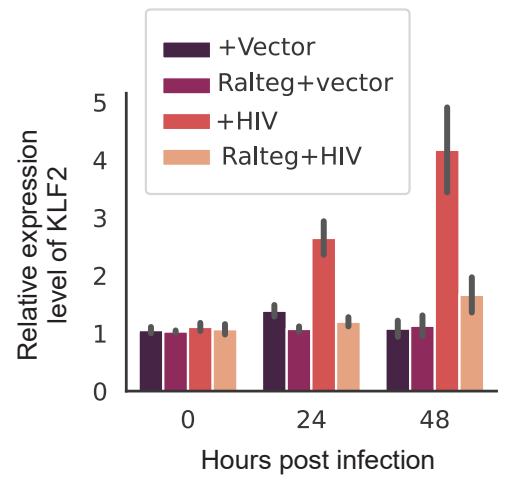

Fig. 3
$\mathrm{H}$
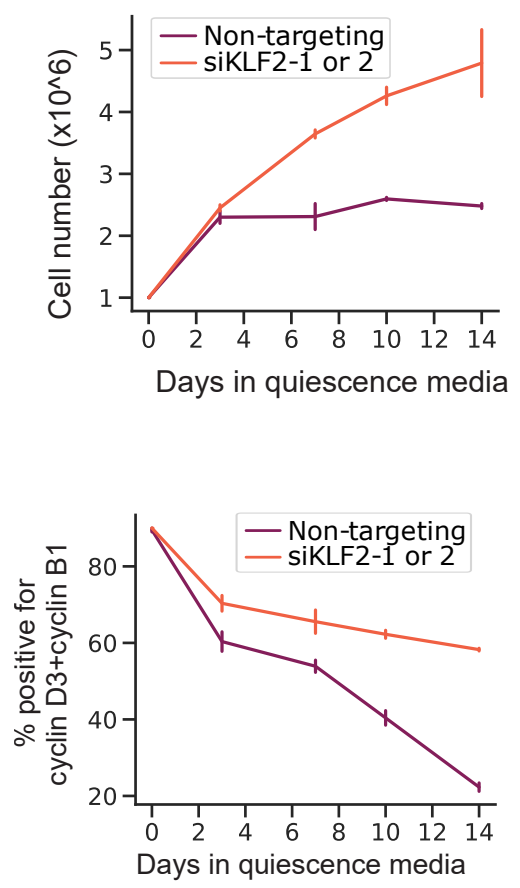
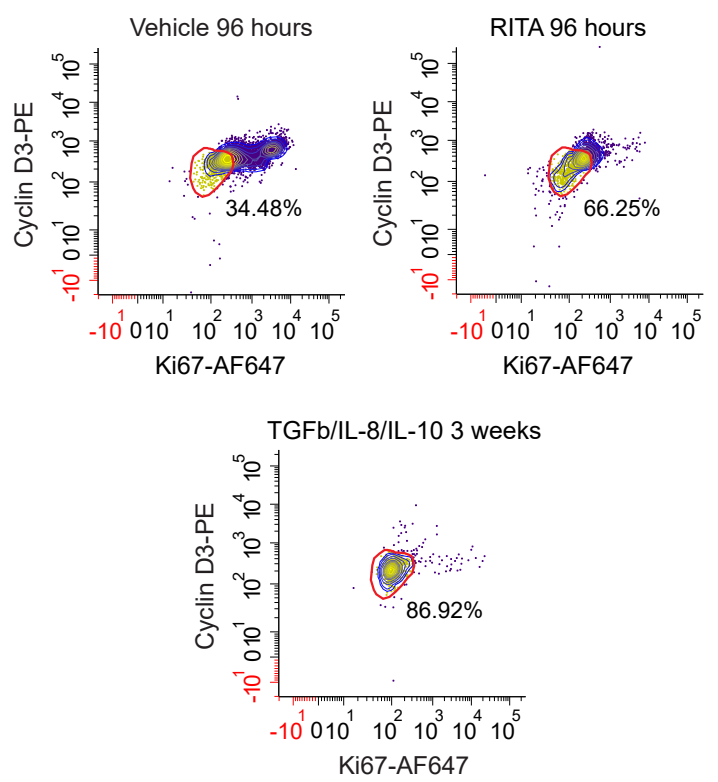

F

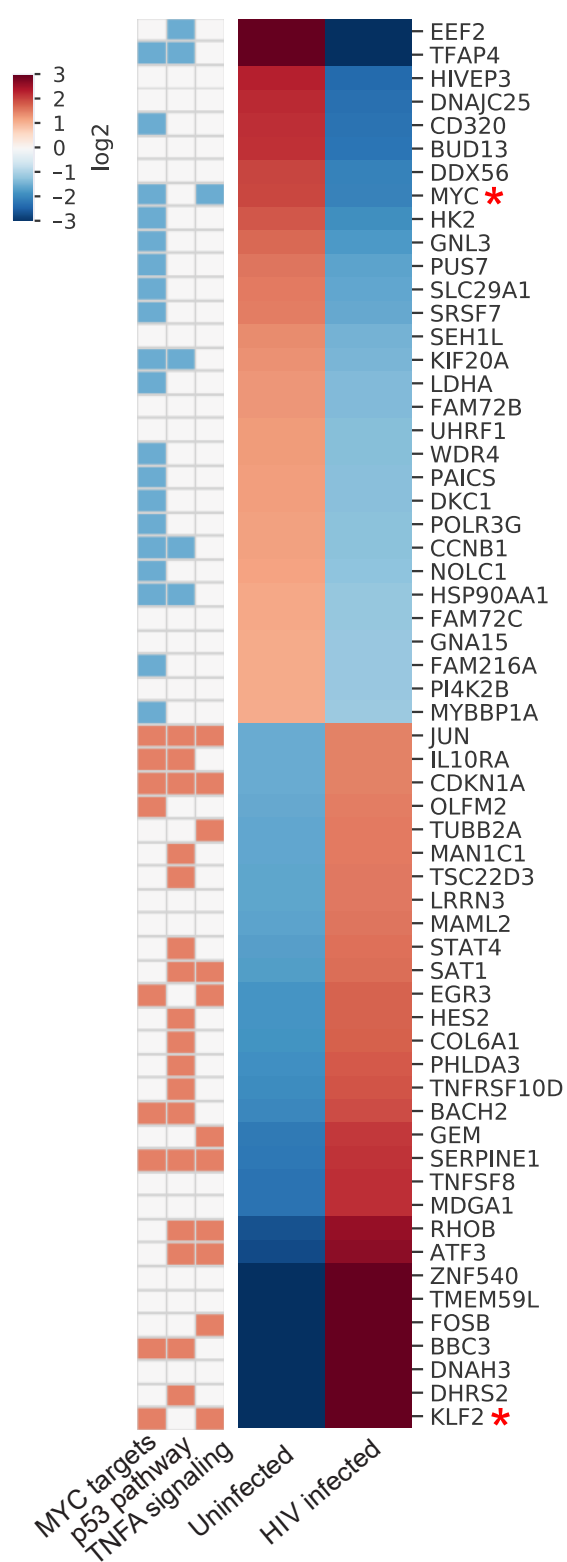


Figure 3. HIV-induced induction of p53 pathway and KLF2 leads to MYC downregulation and loss of proliferation markers.

A. Incubation of primary human CD4+ T cells with the p53 agonist RITA results in nuclear accumulation of p53. B. Induction of p53 activity by RITA leads to slower proliferation in CD4+ T cells incubated in proliferation media. C. Flow cytometry analysis of fully quiescent cells (bottom panel), and proliferative cells incubated in high IL-2 proliferating media that are either treated with vehicle or RITA (left and right panels, respectively) shows the strong downregulation of proliferation markers cyclin D3 and Ki67 in RITA-treated cells after 96 hours. D. P53 pathway activation in isolation leads to downregulation of MYC targets and some additional proliferative Hallmark pathways that are also negatively enriched in HIV-infected cells. Plus and minus signs at the bottom indicate positive or negative enrichment. E. KLF2 is among genes showing the strongest negative correlation to MYC in the main effector cell polarized subtypes. F. Top 30 genes showing the highest level of differential expression in each direction among all datasets studied in Extended Data Fig. 6G include KLF2 as the most strongly upregulated gene and MYC as one of the most downregulated genes (marked by asterisks). The annotation matrix to the left indicates that many of the shown genes are downstream of MYC, p53 and TNF signaling pathways, the top three enriched pathways among genes similarly regulated after HIV infection in all datasets studied in Extended Data Fig. 6G. G. RT-qPCR analysis of KLF2 level in vector or HIV infected primary human CD4+ T cells in the presence or absence of Raltegravir (labeled as Ralteg) confirms the induction of KLF2 after HIV infection and its dependence on proviral integration. $\mathrm{H}$ and $\mathrm{I}$. Knock down of KLF2 prevents entry into quiescence in CD4+ T cells. Proliferating cells were treated with two siRNAs against KLF2 (siKLF2) or a non-targeting control siRNA and were incubated in quiescence-inducing media. Cell number $(H)$ or the fraction of cells positive for both cyclins D3 and B1 (I) was measured at indicated time points. 
A

C
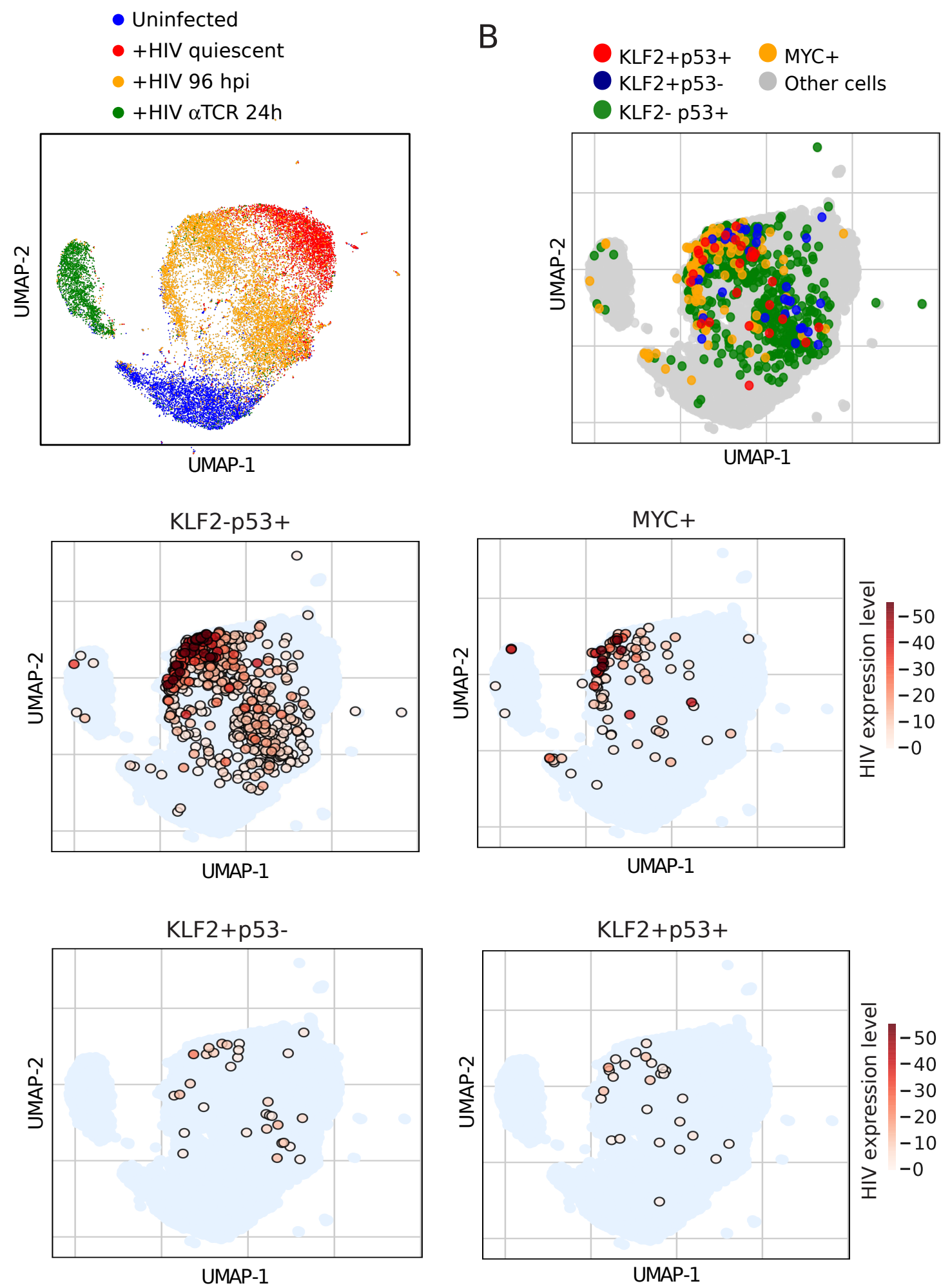

Figure 4

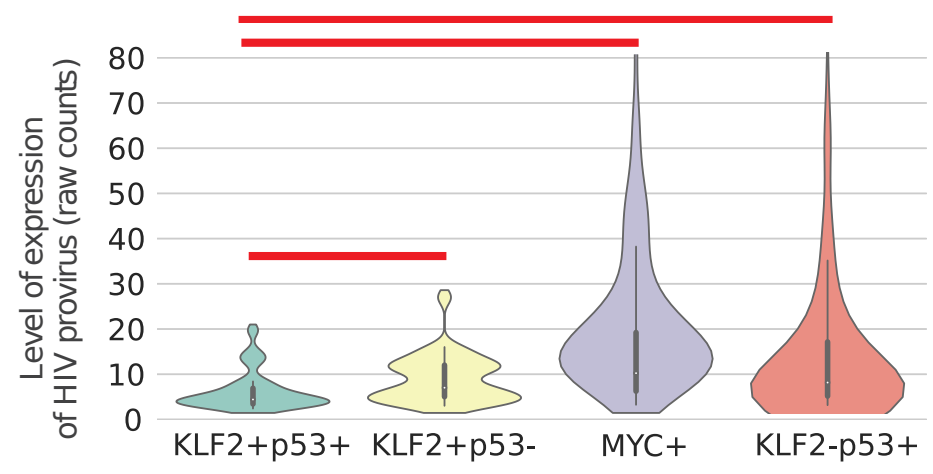


Figure 4. Transcriptional silencing of HIV proviral genome by concomitant activation of KLF2 and p53 after HIV infection.

A. UMAP projection of single cell RNA-seq data show HIV+ 96 hpi cells clustering between uninfected proliferating cells and HIV+ quiescent cells. B. Distribution of +HIV 96 hpi cells expressing MYC, KLF2, p53 pathway genes, or both p53 pathway genes and KLF2. C. Level of expression of HIV provirus in cells expressing p53 pathway genes (top left), MYC (top right), KLF2 (bottom left) or p53 pathway genes and KLF2 in combination (bottom right). D. Proviral transcriptional shutdown is associated with dual activation of p53 and KLF2 signaling. The red bars connecting pairs of samples at the top of the graph indicate a Mann-Whitney $U$ test (MWU) $p$-value $<0.05$. 
Polarization and infection of effector Th17 T cells

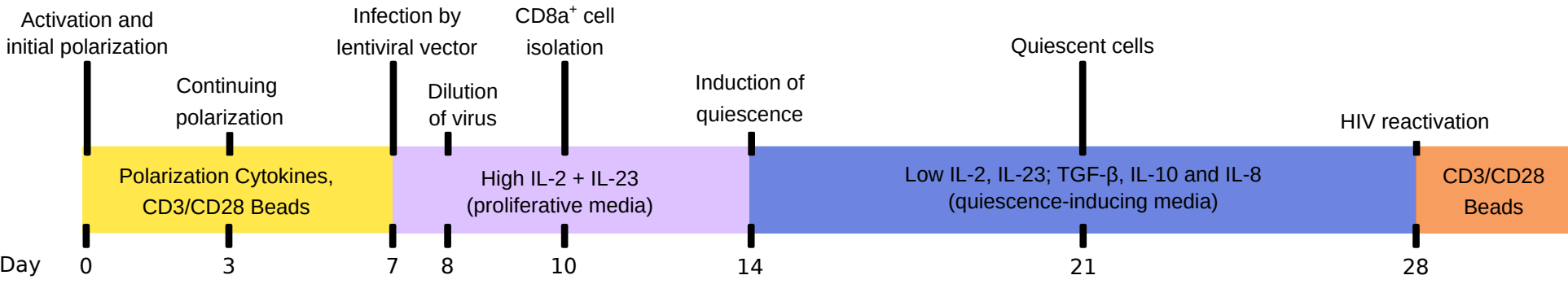

HIV-1 reporter virus

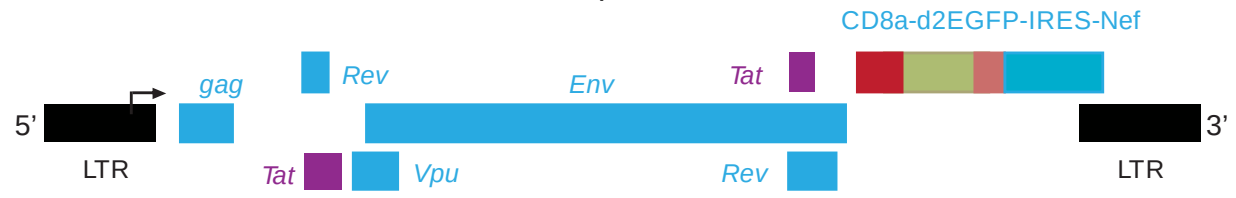

B

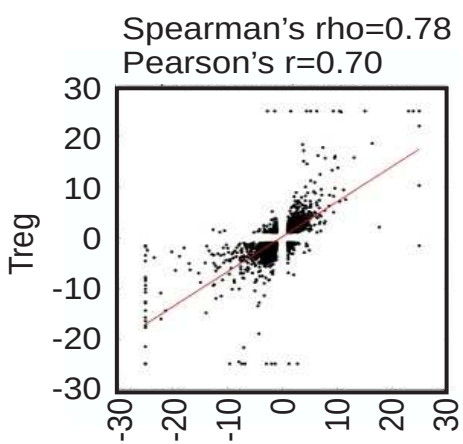

Th17

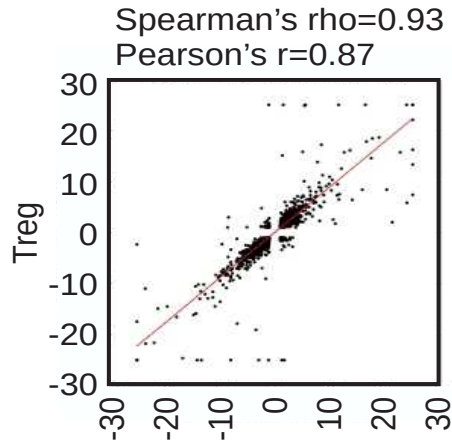

Th2

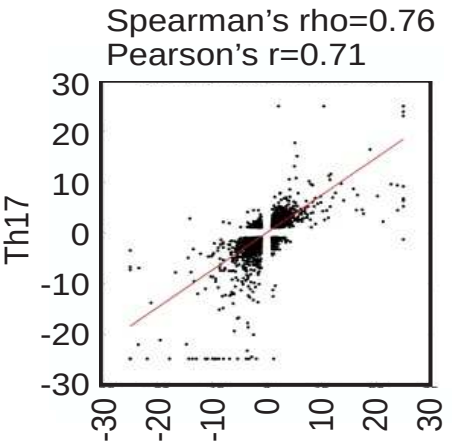

Th2

Spearman's rho $=0.90$

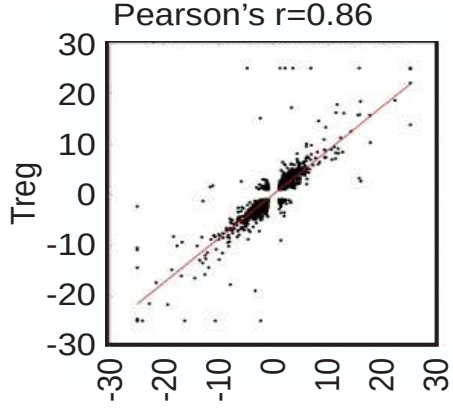

Th1

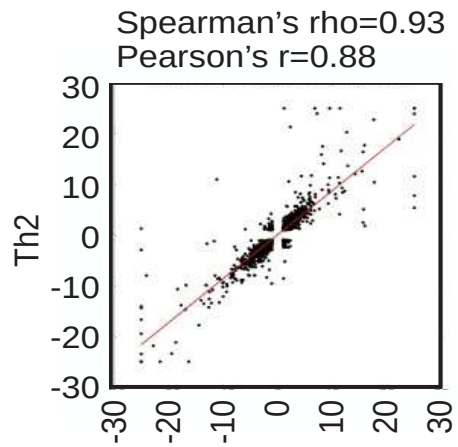

Th1

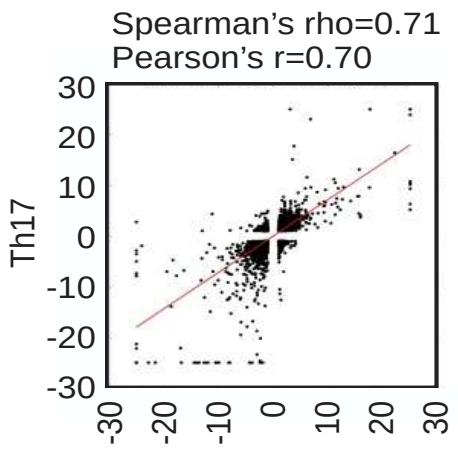

Th1 


\section{Extended Data Fig. 1.}

A. Schematic representation of the ex-vivo CD4+ T cell HIV latency model and HIV reporter construct used in this study. In the HIV reporter construct schematic, the location of each gene is shown, along with the locus of the CD8a-Nef fusion reporter gene. B. Pairwise comparison of the pattern of differential expression of protein-coding genes in response to HIV infection between the four polarized effector cells show pairwise correlation coefficients of 0.7-0.88. Scatterplots indicate the level of correlation of genes differentially expressed after HIV infection (72 hpi) in each polarized cell (>2-fold change, FDR<0.05) against the similar group of genes in the three other polarized cell types. Spearman's and Pearson's correlation coefficients are shown on top of each scatterplot. 


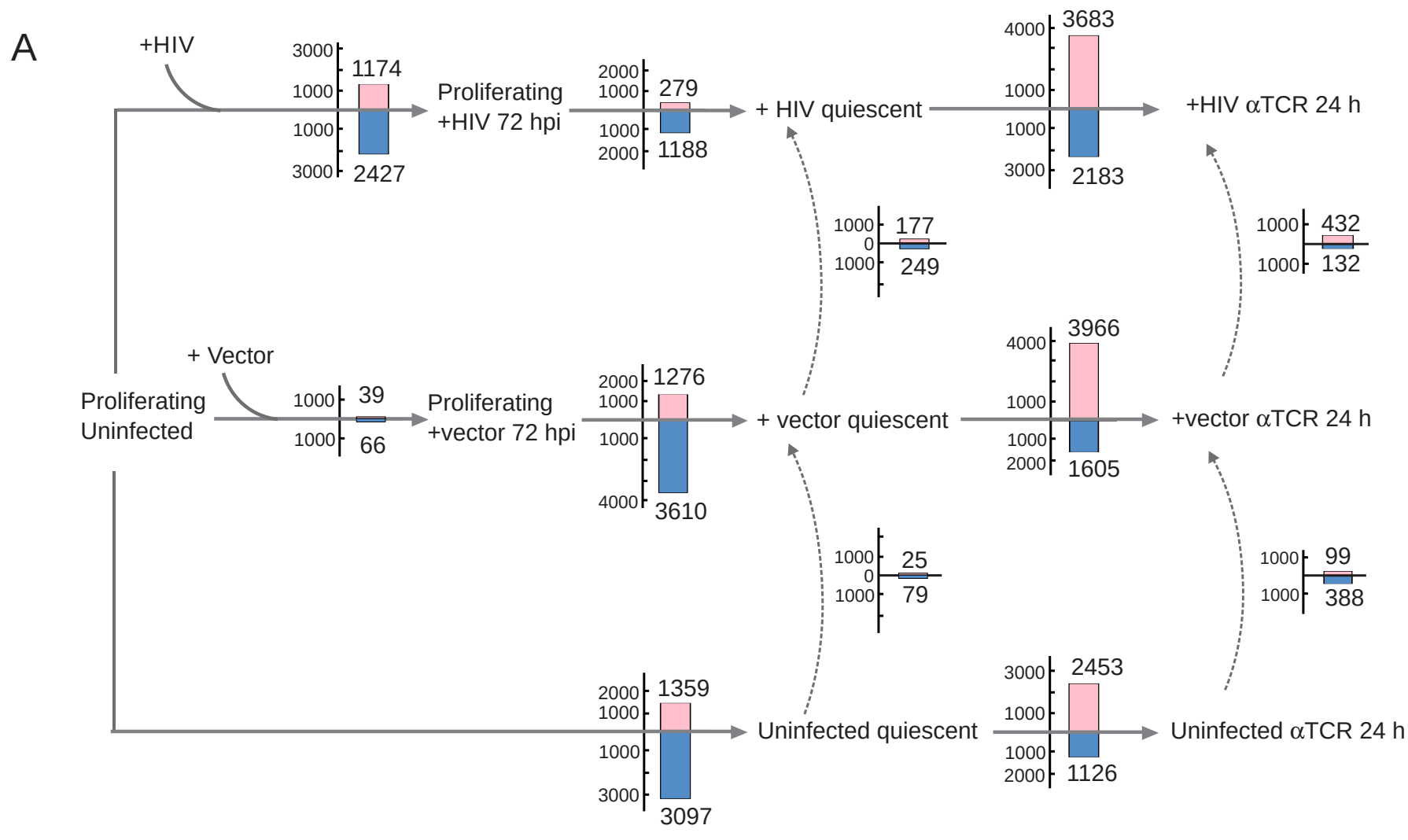

B

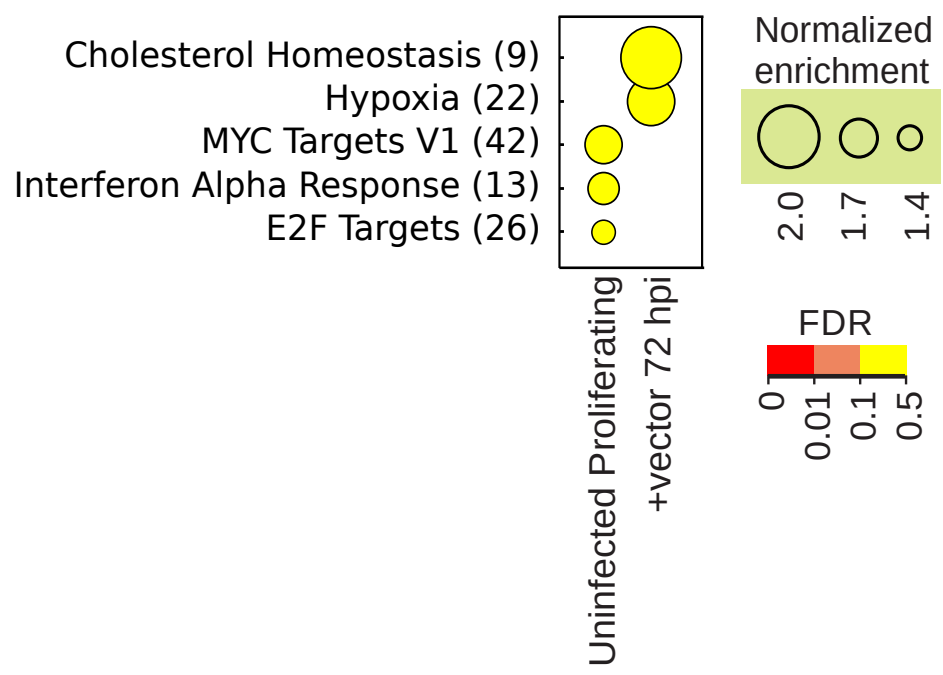

Extended Data Fig. 2 


\section{Extended Data Fig. 2.}

A. Differential gene expression patterns during transition between different stages of HIV and T cell life cycle. Pink and blue bars reflect the number of up and down-regulated protein-coding genes during each transition or comparison, respectively. B. Pathway analysis comparing uninfected proliferating, and +vector 72 hpi cells indicates mild to moderate changes in a small number of pathways with marginal statistical significance. Pathways positively enriched under each condition are shown. Numbers between parentheses indicate the number of genes in each gene list that drive the enrichment phenotype (see Materials and Methods). 
GO energy derivation by oxidation NAD metabolic process $\mathrm{GO}$ structural constituent of ribosome GO glucose catabolic process GO rRNA metabolic process GO RNA splicing via transesterification reactions
GO ATP generation from ADP GO RNA splicing via transesterification reactions
GO ATP generation from ADP ino acid biosynthetic process GO NADH metabolic process GO RNA splicing GO cellular respiration GO monosaccharide catabolic process GO monosaccharide catabolic process
GO mRNA processing
GO coenzyme metabolic process GO ADP metabolic process GO hexose catabolic process GO regulation of cellular protein catabolic process GO regulation of lipoprotein metabolic process GO ribonucleoside diphosphate metabolic process GO regulation of cellular amino acid metabolic process GO RNA end processing

GO serine family amino acid metabolic process GO coenzyme biosynthetic process $\mathrm{GO}$ amide biosynthetic process GO terpenoid metabolic process GO proteoglycan metabolic process GO proteoglycan biosynthetic process $\mathrm{GO}$ aminoglycan biosynthetic process regulation of lipid biosynthetic process GO positive regulation of lipid biosynthetic process $\mathrm{GO}$ arachidonic acid metabolic process $\mathrm{GO}$ positive regulation of lipid metabolic process GO positive regulation of fatty acid biosynthetic process

Normalized enrichment

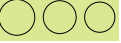

$\infty$ ^

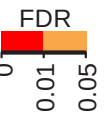

C

Genes downregulated during entry into quiescence

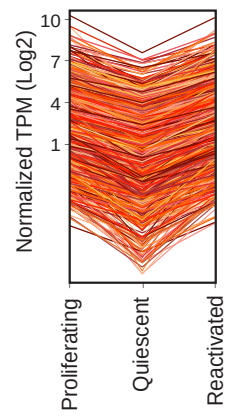

Genes upregulated during entry into quiescence

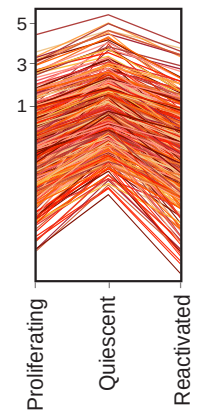

E

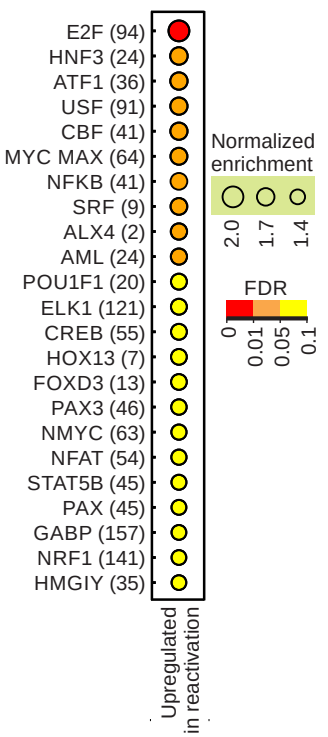

$$
\begin{array}{r}
\text { MYC targets v1 (158) } \\
\text { E2F targets (122) } \\
\text { MYC targets V2 (47) } \\
\text { TNFA signaling via NFKB (48) } \\
\text { G2M checkpoint (137) }
\end{array}
$$
MTORC1 signaling (111) Oxidative phosphorylation (144) IL2 STAT5 signaling (38) UV response up (57) Estrogen response late (40) Epithelial mesenchymal transition (21) Glycolysis (75) meostasis (29) DNA repair (75) Unfolded protein response (67)
Hypoxia (41)
Fatty acid metabolism (58) Unfolded protein response (67)
Hypoxia (41)
Fatty acid metabolism (58) Fatty acid metabolism (58) Allograft rejection (27) Apical junction (16) Apical junction (16)
Interferon alpha response (42)
B

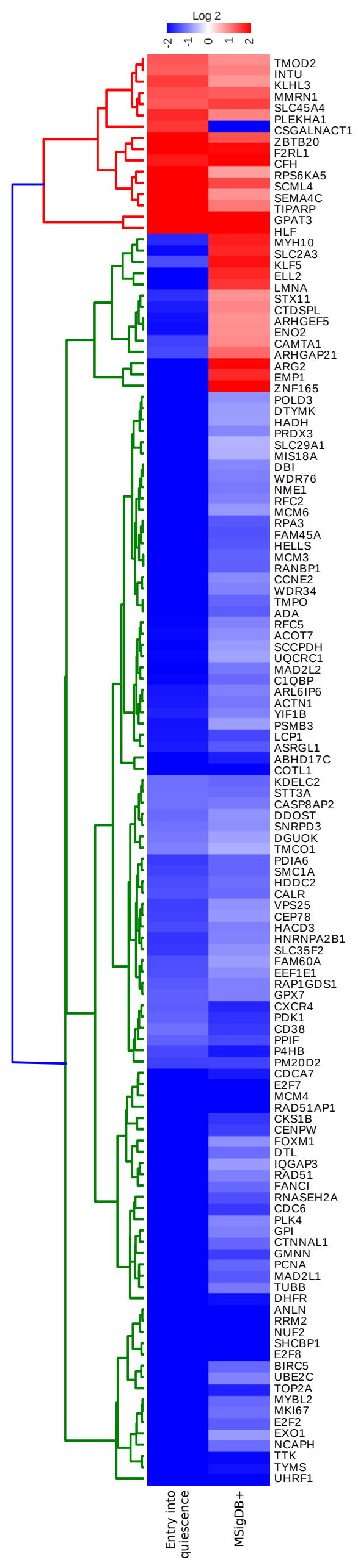

Normalized enrichment $\mathrm{OOO}$

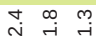
FDR

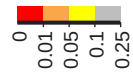




\section{Extended Data Fig. 3.}

A. Transition into quiescence leads to downregulation of cellular metabolic pathways. The metabolic process subset of gene Ontology (GO) pathways that are differentially enriched in either the positive or negative direction during transition from proliferative state to quiescence in vector-infected cells with an FDR $<0.05$ were included in the graph. B. Genes showing differential expression (defined as $>2$-fold change with FDR $<0.05$ ) during transition from proliferating to quiescent state in vector-infected cells closely match the genes in quiescence pathways in $\mathrm{mSigDB}$ and other studies of quiescence (mSigDB+, see Materials and Methods). C. A large fraction of protein-coding genes show symmetric changes in expression during entry and exit from quiescence. The genes that decrease and increase in expression during entry into quiescence are shown in the left and right panels, respectively. Each line corresponds to the pattern of changes in the expression of a single differentially expressed gene. The number of genes included in each graph (showing $>2$-fold change with FDR<0.05 during both transitions) is shown above each panel. D. and E. Transcription factors (D) and pathways (E) that show altered activity or enrichment in uninfected and +vector $\alpha$ TCR $24 \mathrm{~h}$ cells. Numbers between parentheses indicate the number of genes in each gene list that drive the enrichment phenotype (see Materials and Methods). 


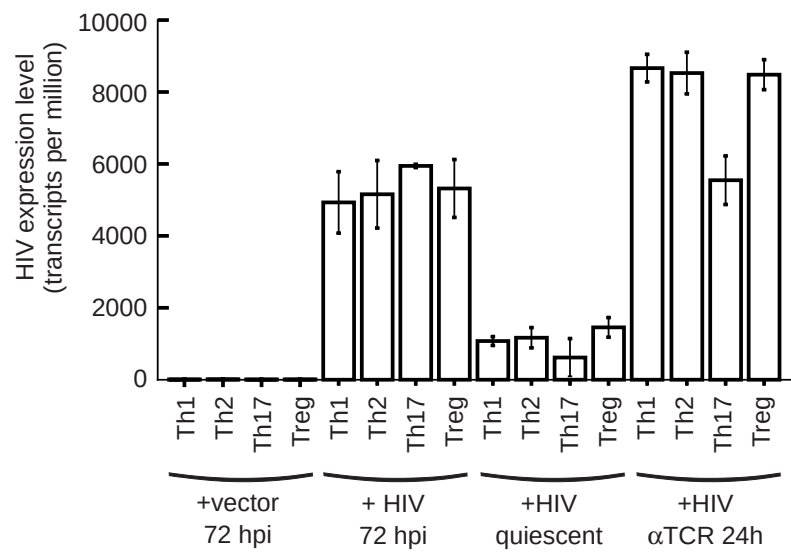

D

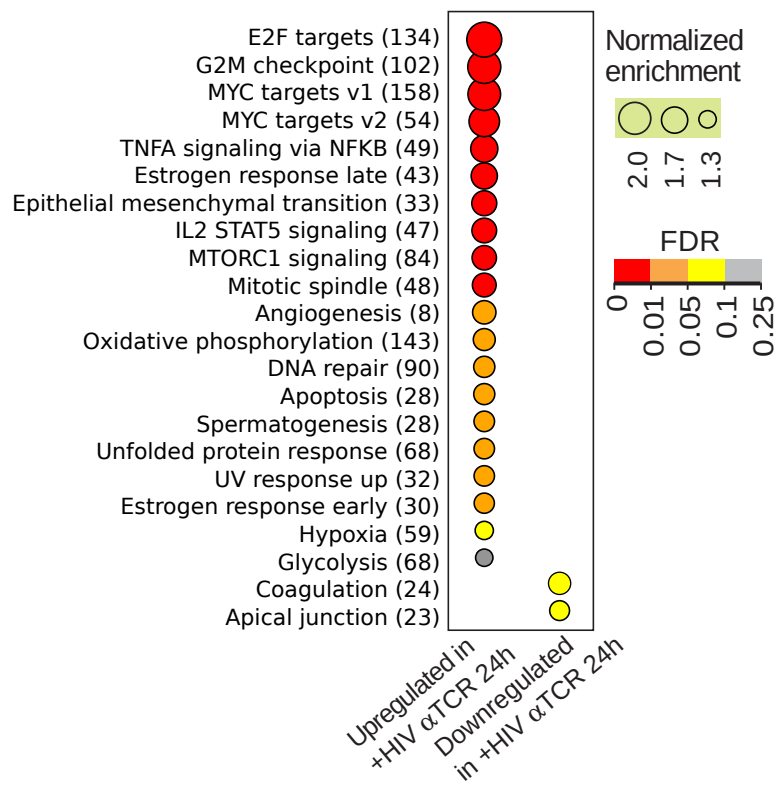

G
F Fold change $(\log 2)$

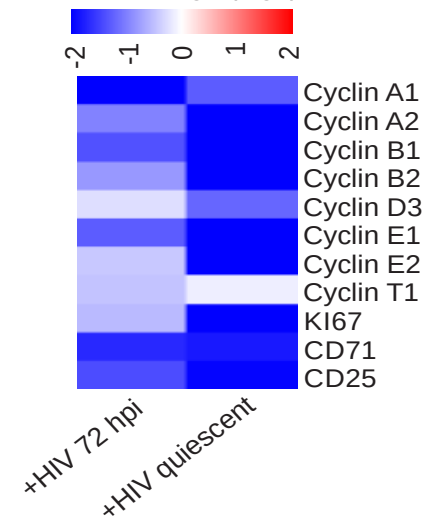

E

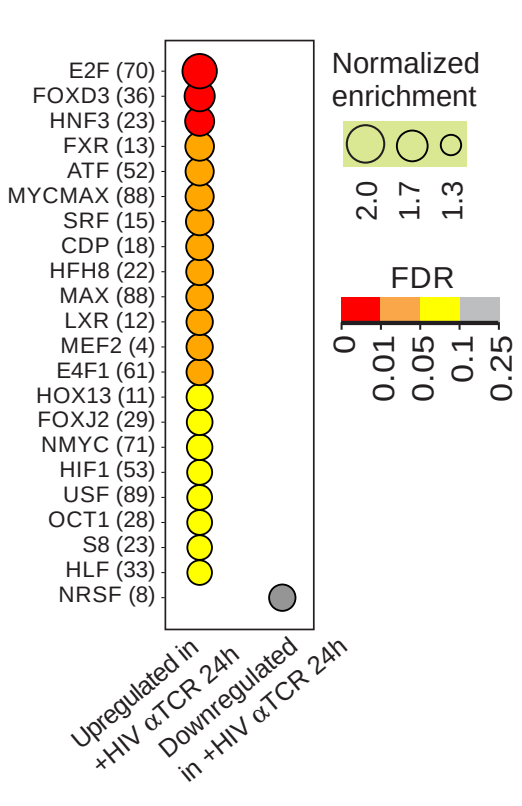
G2M CHECKPOINT (142) OXIDATIVE PHOSPHORYLATION (137)
OAL MES MTORC1 SIGNALING (125)

ESTROGEN RESPONSE LATE (46) HYPOXIA (46) GLYCOLYSIS (89)

KRAS SIGNALING DN (24) UNFOLDED PROTEIN RESPONSE (69) ADIPOGENESIS (77) SPERMATOGENESIS (39) UV RESPONSE DN (23)

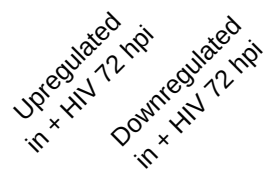

Normalized Fold change ( $\log 2)$ enrichment $\infty \quad \forall \quad \forall \quad \infty$
MC5R GPR152 B3GALT2 SMPD3 RFN2 AR ZBP1

CD96

KLF2

TMEM221

SMIM10L2A

ACER1

CACNA1D

CACNA1D

TMEM229

SRT5

SLC52A1

KLRB1

NLRP6

CDHR2

PTGDR2

PTPRO

PGGHG

COLQ

CXCR6

TNS1

KCNB1

TAS2R30

SLC36A2

RNF144A

FCGBP

TCP11L2

TNFRSF10A

MXD4

ITM2B

GRID2IP

GPRASP1

SCML1

TMEM63

TMEM63A

YPEL3

ADAMTS

LZTS3

TMEM150A

PDE3B

GPR35

SLC35D2

CUBN

PMEL

GLT1D1

ABCG2

MAP1B

RIMKLA

ARFGEF3

RAB32

TEAD4

TCEAL9

SCARB1

EPDR1

SHB

GLB1L2

P4HA2

B4GALT2

AK4

AK4
EAF2

NRIP3

CLGN

CLGN

MYB

HILPDA

SLC16A9

ANKR

ANKRD37

DGKG

NAPSA
SMIM10

FABP5

E2F5

PLOD2

MT1C

PYGL

GALNT18

TUBB3

TERT

GATM

ABCA1

MAPK12

KISS1R

KIF26A

YBX2

PFKFB4

PTPRF

CENPV

CAVIN3

CAVIN3

CCNA1

BATF3

MYOF

ARMCX1

ZBTB32

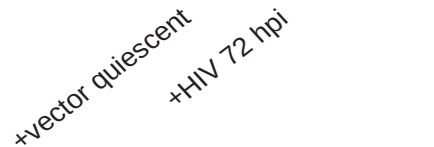




\section{Extended Data Fig. 4.}

A. Changes in the expression level of the HIV provirus in +HIV $72 \mathrm{hpi},+\mathrm{HIV}$ quiescent and $+\mathrm{HIV} \alpha \mathrm{TCR}$ $24 \mathrm{~h}$ conditions in the four main polarized subtypes of effector CD4+ T cells. The $Y$ axis indicates the number of transcripts per million cellular transcripts. +vector $72 \mathrm{hpi}$ cells are included as negative control. B. HIV infection leads to downregulation of multiple cellular growth pathways including MYC and E2F transcriptional cascades and upregulation of p53 signaling. For this panel and panels D and $\mathrm{E}$, numbers between parentheses indicate the number of genes in each gene list that drive the enrichment phenotype (see Materials and Methods). C. A large fraction of genes differentially expressed in +HIV 72 hpi cells compared to +vector 72 hpi and uninfected proliferative cells (2660 of -3600 genes, Extended Data Fig. 2A) correspond to the genes differentially expressed during entry into quiescence in the absence of HIV (in +vector and uninfected cells). The top 50 most differentially expressed among these correlated genes in each direction are shown. D. and E. Pathway analysis (D) and transcription factor activity analysis (E) in +HIV $\alpha$ TCR $24 \mathrm{~h}$ cells indicate that many of the pathways upregulated during reactivation from quiescence correspond to those downregulated in +HIV 72 hpi cells. F. Most cyclin genes show a weak downregulation in +HIV 72 hpi cells and a much stronger one upon entry into full quiescence (+HIV quiescent cells). Ki67 proliferation marker is included to indicate the extent of inhibition of proliferation. G. Following exposure of primary CD4+ T cells to HIV reporter virus, over half of the population becomes productively infected based on flow cytometry measurement of the level of expression of the GFP reporter gene. The values shown correspond to 2 days post infection. 
DTL

RFC3

FEN1

CDC6

BUB1B

GINS1

BUB1

MELK

CCNE1

SNRNP25

RNASEH2A

GMNN

ATP5G3

MCM5

CEP55

MSH2

ZWINT

TK1

MAD2L1

CDC20

SMC2

DLGAP5

VDAC3

CKS1B

NUP85

HAT1

KIF2C

TYMS

CCNA2

CCNA2
NDC80

DSCC1 1

KIF11

RRM1

LEPR

COTL1

PRC1 1

GGH

DHFR

CDK1

CDKN2

PCNA

CENPM

RACGAP1

MINPP1

RBPMS

DST

FXR1

EVI2A

KYNU

TSPAN31

PMCH

ALOX5

TSTS4

TNFSF4

HIST2H2BE
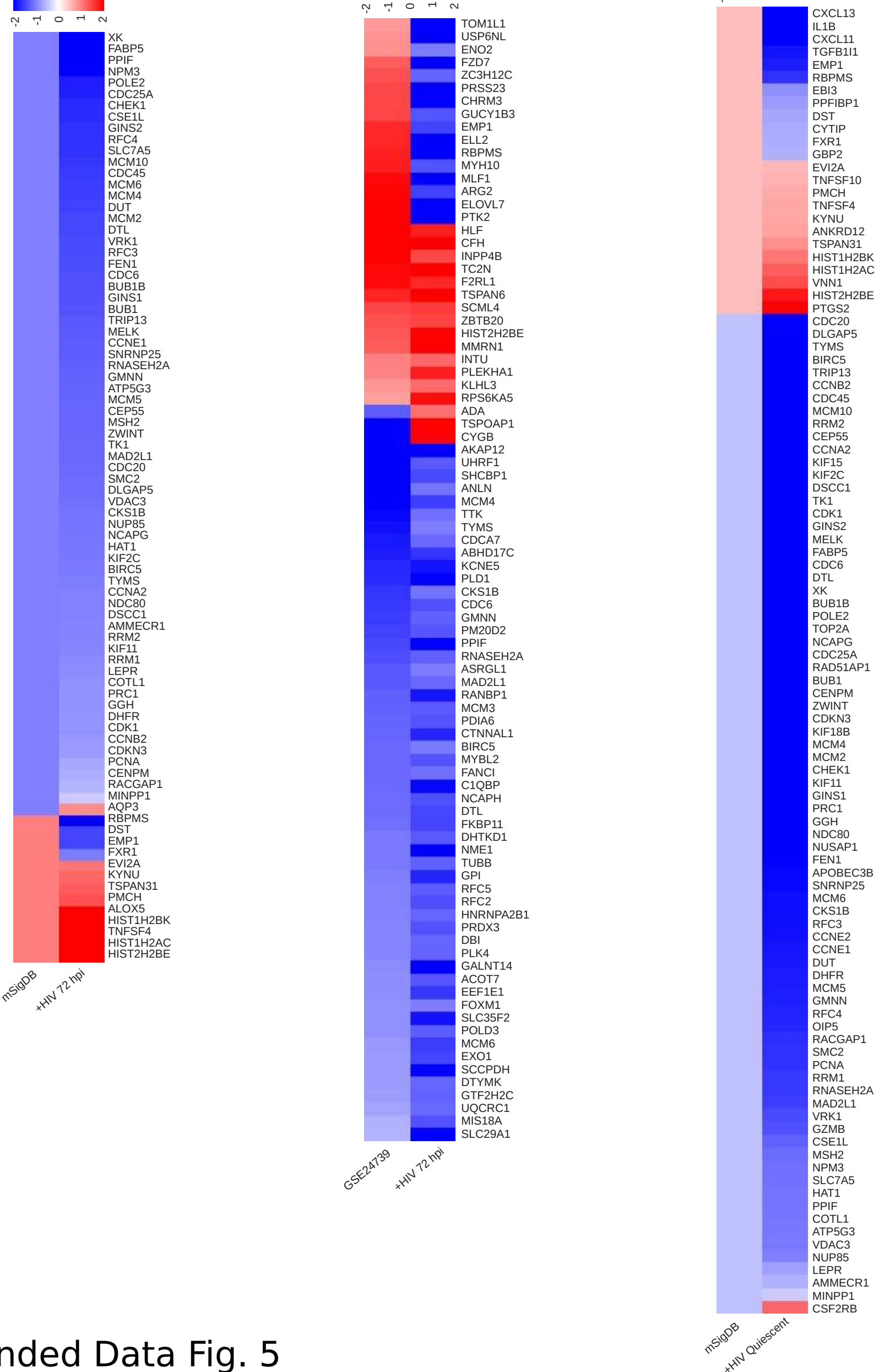


\section{Extended Data Fig. 5.}

A. HIV infection leads to changes in gene expression that is characteristics of quiescent cells. The column to the left reflects the expected pattern of change in genes that constitute the molecular signature of quiescence. B. The pattern of change in gene expression after HIV infection closely resembles that following entry into quiescence in hematopoietic stem cells (lane labeled GSE24739, see Materials and Methods). C. Pattern of gene expression change after entry of HIV infected cells into full quiescence closely resembles that observed during quiescence in other cells, as reflected in the quiescence signature pathways in $\mathrm{mSigDB}$. Genes expected to be up or downregulated in quiescence are shown in the lane marked mSigDB with pink and light blue color, respectively. 


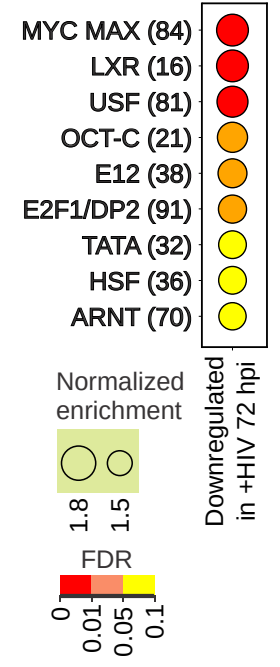

D

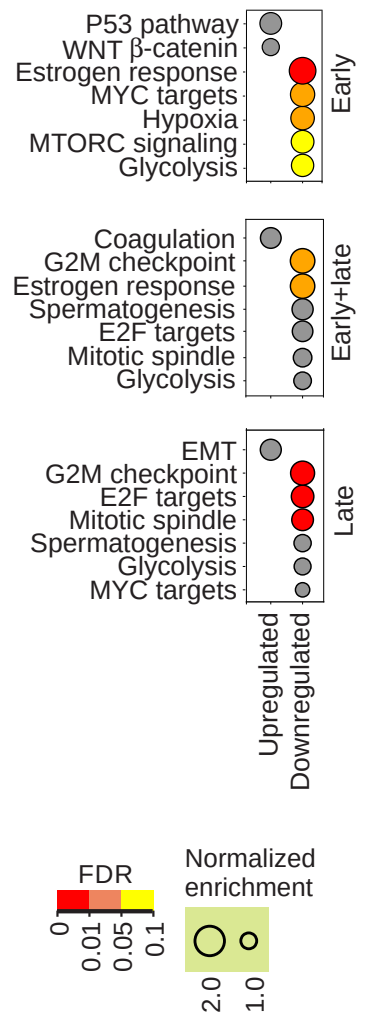

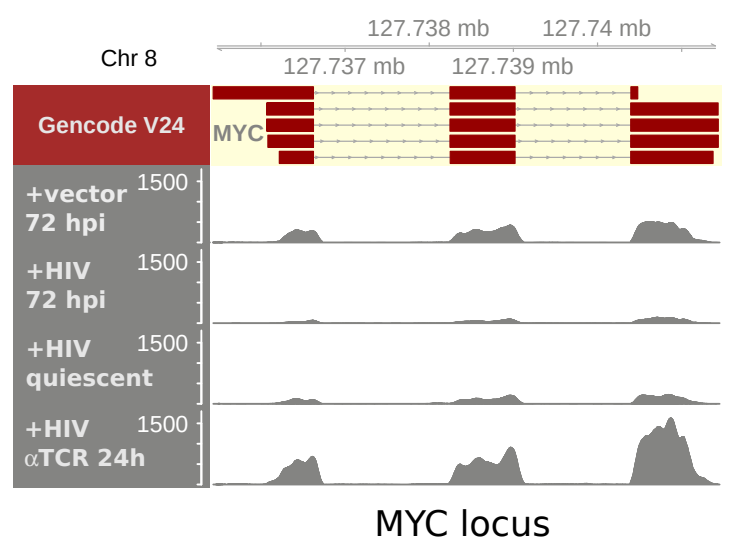

$E$

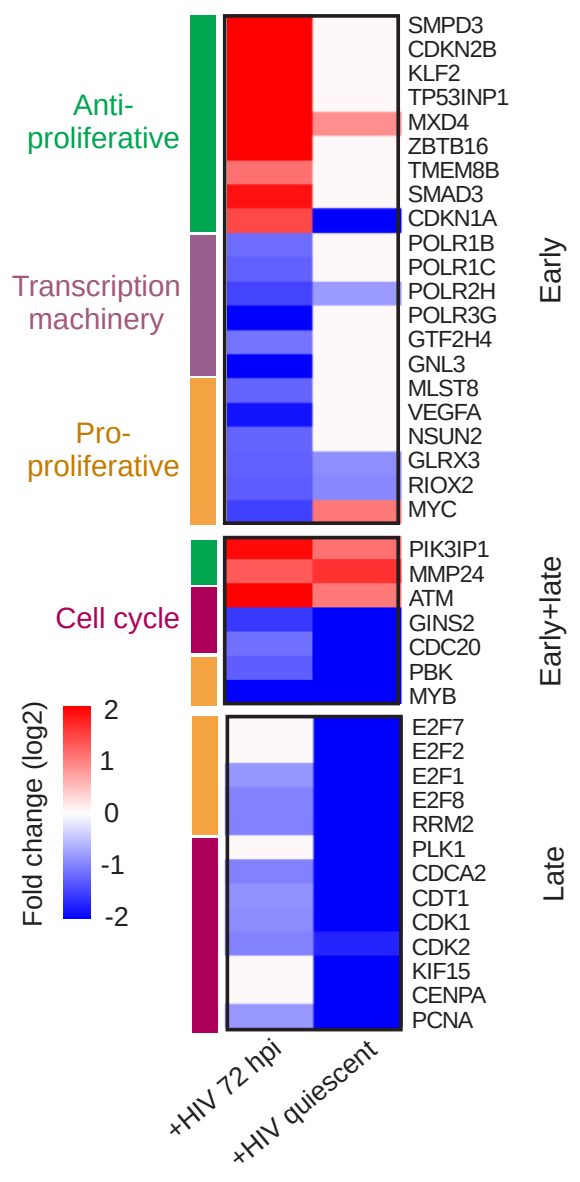

F

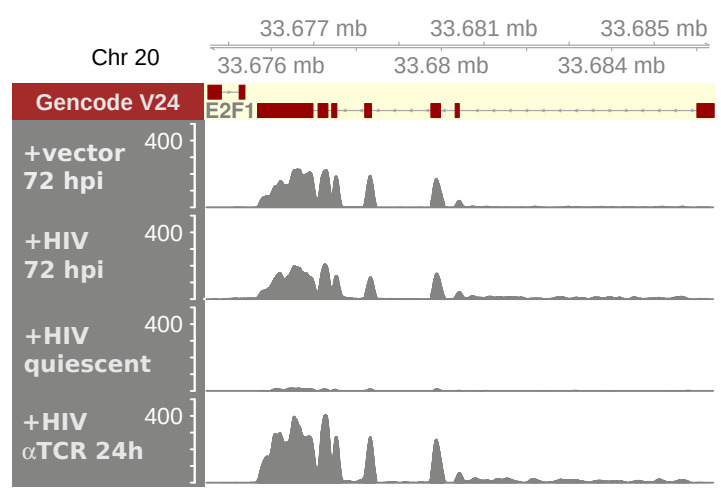

E2F1 locus

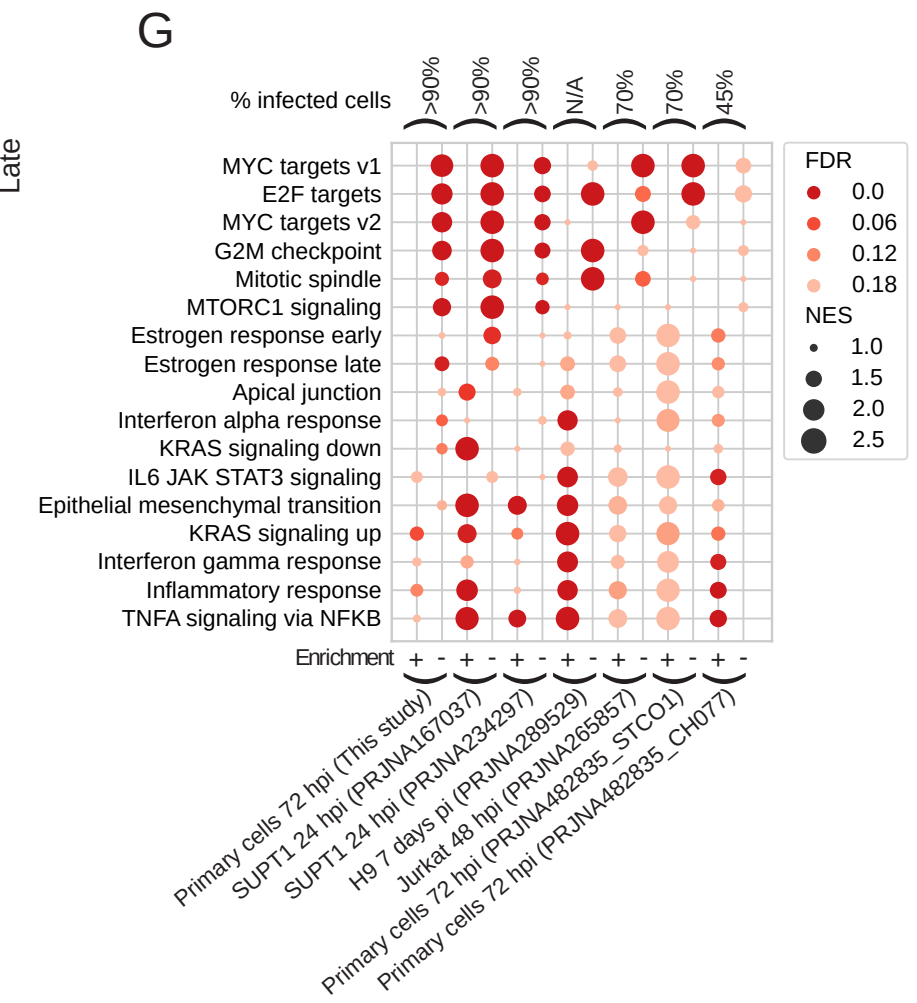




\section{Extended Data Fig. 6.}

A. The activity of a number of proliferation-inducing transcription factors, especially MYC, is strongly reduced in +HIV 72 hpi cells. Numbers between parentheses indicate the number of genes in each pathway that drive the enrichment phenotype (see Materials and Methods). B. Reads mapping to MYC in Th17 cells during different stages in HIV and T cell life cycle. C. Temporal pattern of the gene expression changes occurring during the life cycle of HIV infected CD4+ T cells. The number of genes falling into early, late, and early+late categories is written above each box. Genes showing an overall pattern of down- and upregulation are shown in the left and right boxes, respectively. The expression values are graphed as log2 transformed transcript per million (TPM) values, with each line representing a gene. The line graphs indicate the level of expression of each gene in the four cellular states shown at the bottom of each column of line graphs. D. Pathway analysis results on genes in each category in panel C. E. Heatmap of the top differentially expressed genes in each category shown in panels $C$ and $D$. The color bars to the left show the functional classification of each group of genes. F. Reads mapping to E2F1 in Th17 cells during different stages in HIV and T cell life cycle. G. Pathway analysis using Hallmark gene lists on seven independently performed high throughput transcriptomic studies of cells in early time points after HIV infection point to MYC signaling as the most strongly downregulated pathway after HIV infection. The percentage of infected cells in the sequenced population of each dataset is indicated on top. N/A: not available. Cells used and time point of infection along with project accession numbers are shown at the bottom. The two primary HIV isolates studied in PRJNA482835 (STCO1 and CH077) are graphed separately. 
A

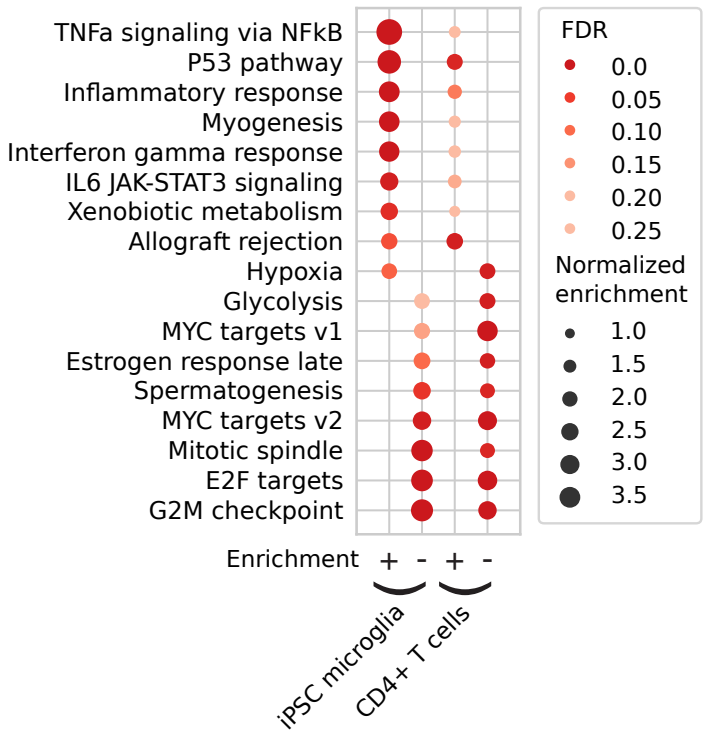

B

C

HIV infected vs. uninfected iPSC-derived microglia

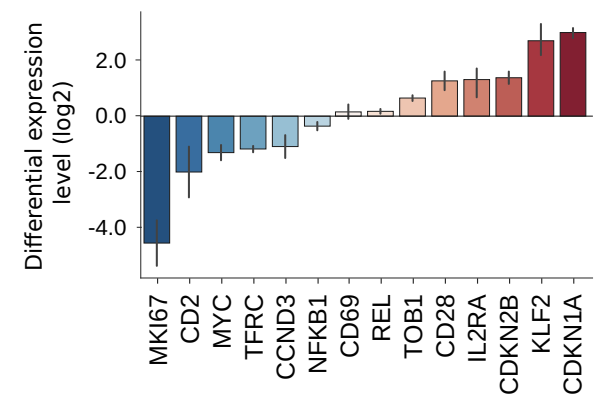

iPSC-derived microglia

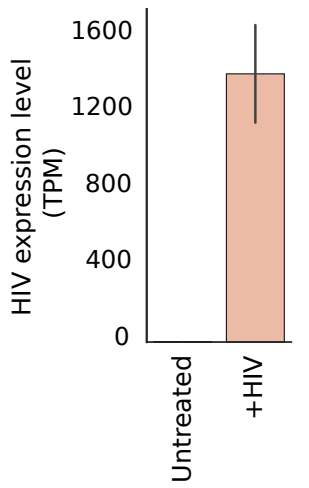

$\mathrm{D}$

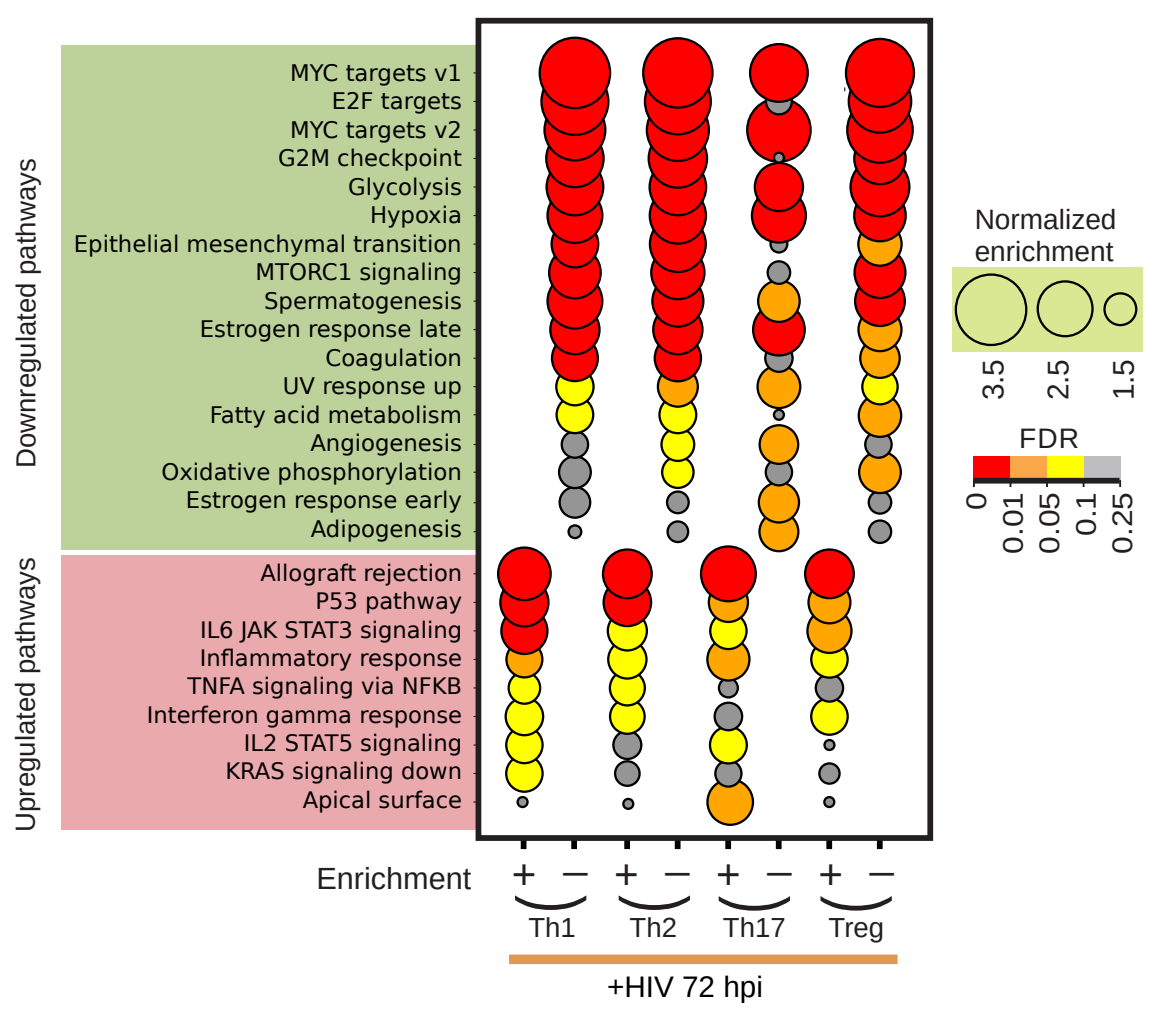

$E$

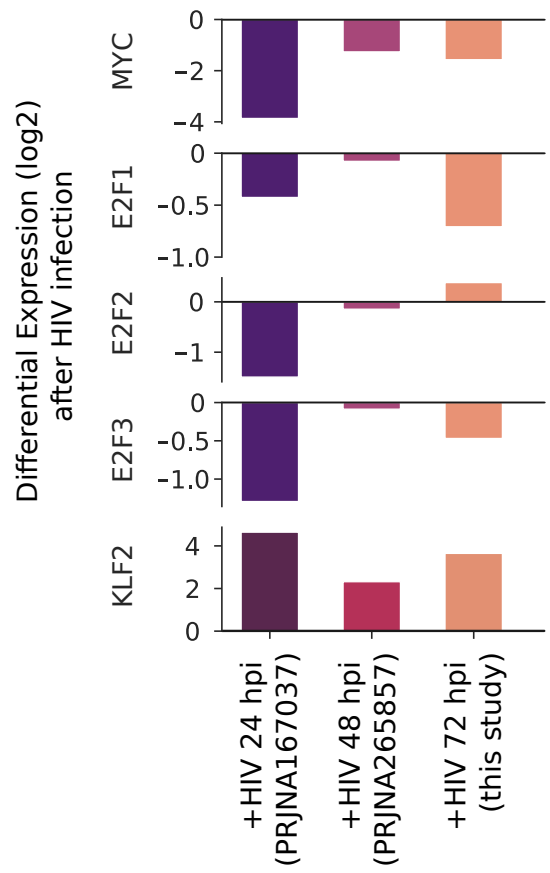

\section{Extended Data Fig. 7}




\section{Extended Data Fig. 7.}

A. HIV infection in iPSC derived microglia leads to a closely similar transcriptomic pattern to the one observed in CD4+ T cells, including downregulation of key proliferative pathways. B. Changes in the expression of markers of quiescence and proliferation following HIV infection in iPSC derived microglia point to induction of a dormant phenotype in these cells. C. High throughput transcriptomic data collected from iPSC derived microglia described in A and B indicate that HIV proviral RNA was expressed at $>1200$ transcripts per million (TPM) in HIV infected samples. D. Pathway analysis results indicate that in all four main subclasses of polarized effector T cells, HIV infection leads to the induction of the signature of entry into quiescence. Plus and minus signs at the bottom indicate positive and negative enrichment of pathways, respectively. E. Across multiple high throughput transcriptomic studies, HIV infection leads to strong and reproducible reduction and increase in the expression of MYC and KLF2, respectively. Milder downregulation of E2F family members is observed in some but not all studies. Please note that the $Y$ axis is scaled differently for each of the stacked panels. 


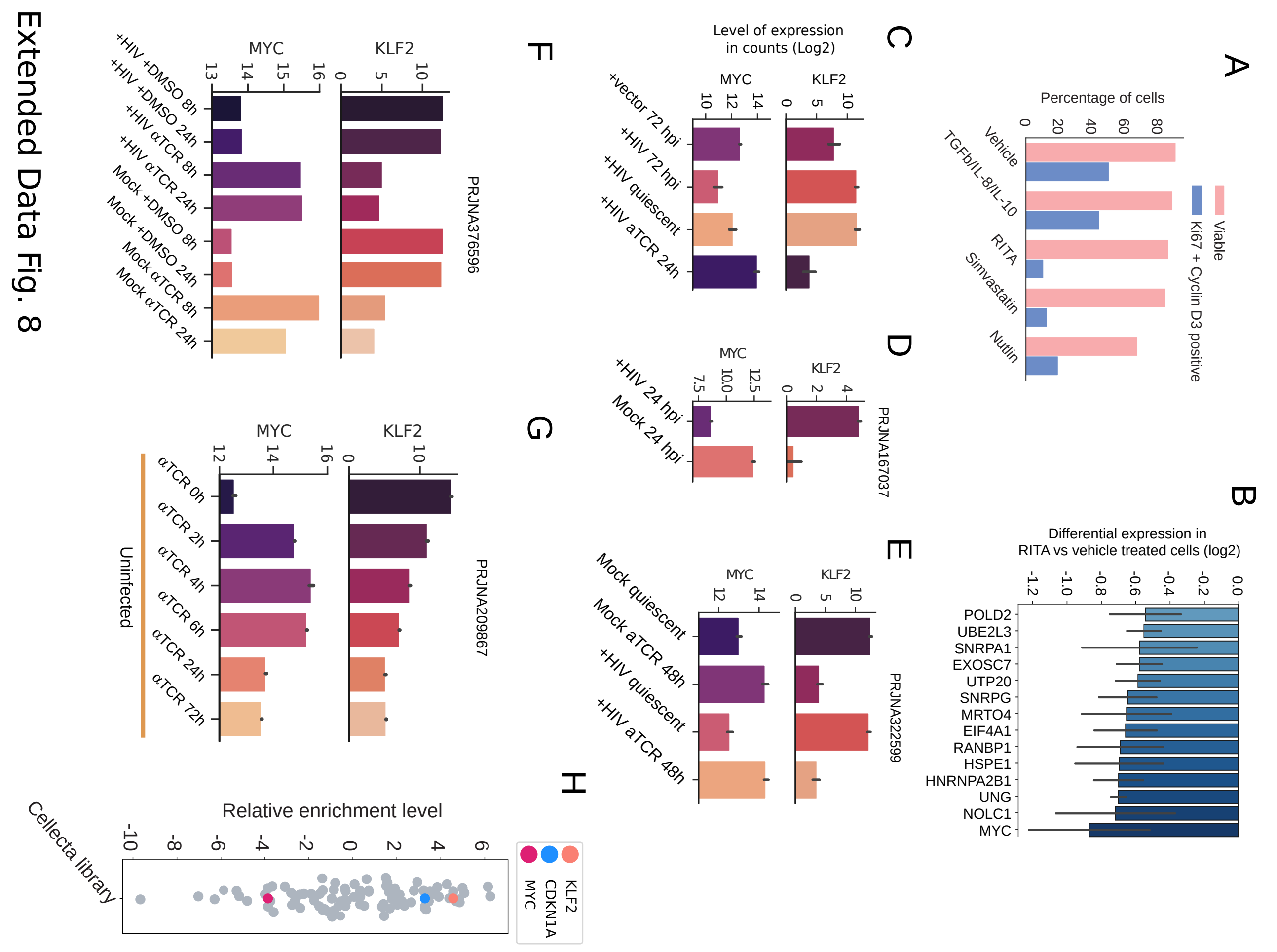




\section{Extended Data Fig. 8.}

A. The percentage of viable cells and those double positive for both Ki67 and Cyclin D3 are shown for proliferating cells incubated in high IL-2 proliferative media that are either treated with vehicle, TGF- $\beta /$ IL-8/IL-10 quiescence inducing cocktail, the p53 agonists RITA and Nutlin, or the KLF2 inducer Simvastatin. B. MYC and several known targets of MYC involved in transcription, translation and cell cycle regulation are downregulated in CD4+ T cells 24 hours after treatment with the p53 agonist RITA. C. KLF2 and MYC show negatively correlated changes in expression during the different stages of HIV and T cell life cycle. D-G. Expression of MYC and KLF2 show negative correlation in several independently performed high throughput sequencing studies, including HIV infection in SUPT1 cells (D), two primary ex-vivo CD4+ T cell HIV latency model studies (E, F) and a primary CD4+ T cell activation time course study in the absence of HIV $(G)$. H. Unbiased shRNA screen results point to KLF2 as a gene critical for maintenance of cellular quiescence and proviral latency. Similarly, the negative enrichment of MYC points to its critical role in maintenance of cellular proliferative state and/or transcriptional activity of the HIV provirus. Each shRNA screen hit is shown as a circle, with the relative enrichment of each gene shown on $Y$ axis. The milder positive enrichment of a p53-induced negative regulator of cellular proliferation, CDKN1A/p21, is also shown. 


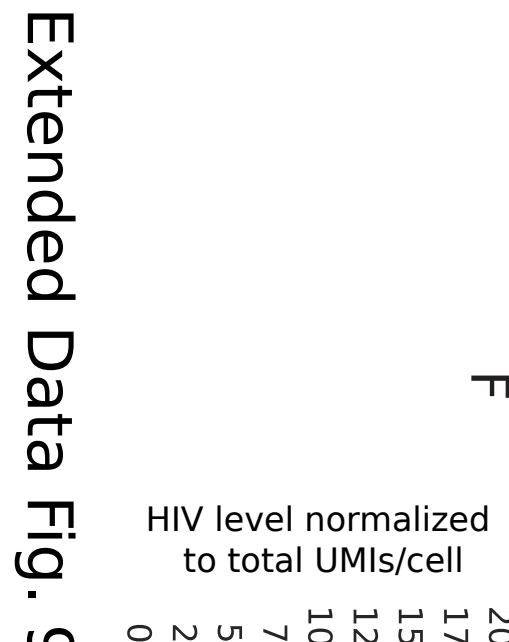

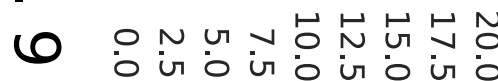

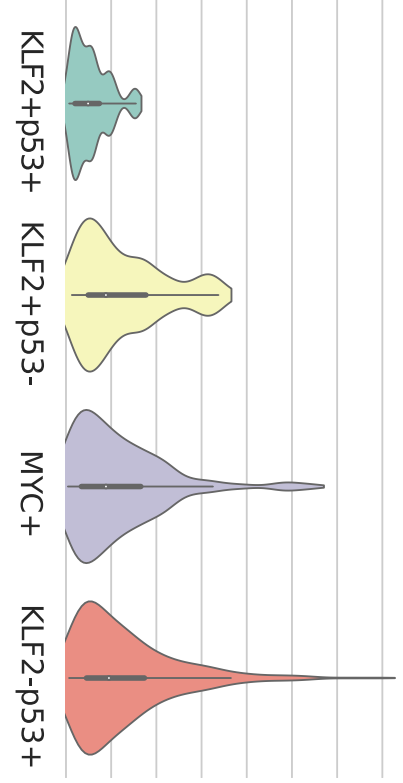

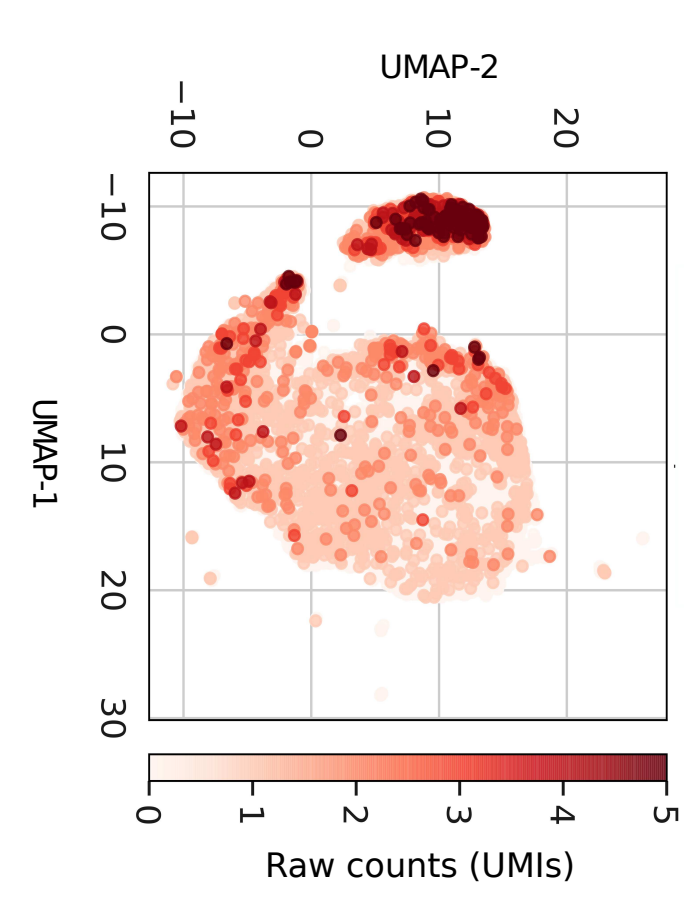

$\cap$

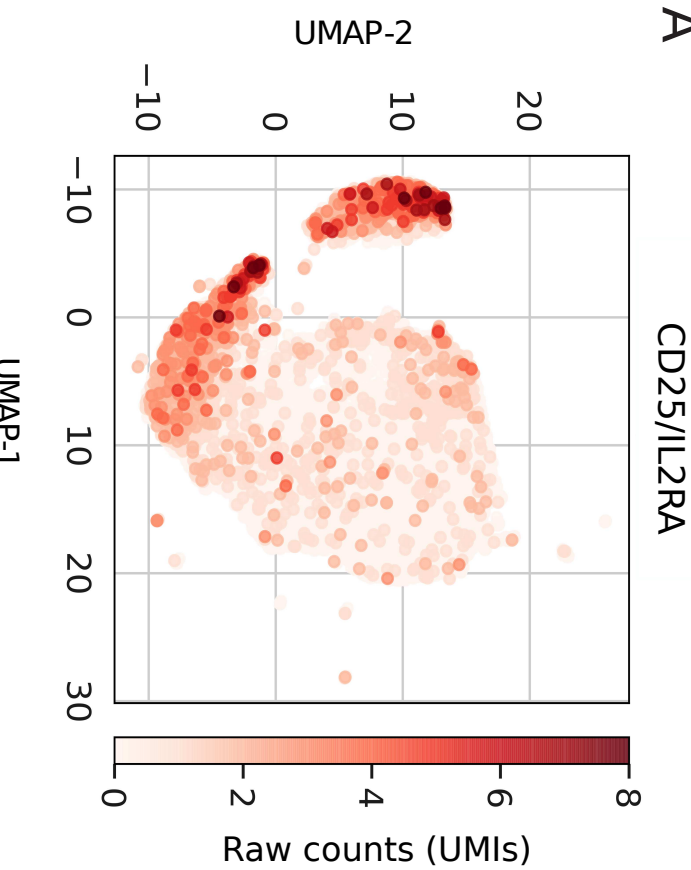

Total number of Raw counts (UMIs) per cell
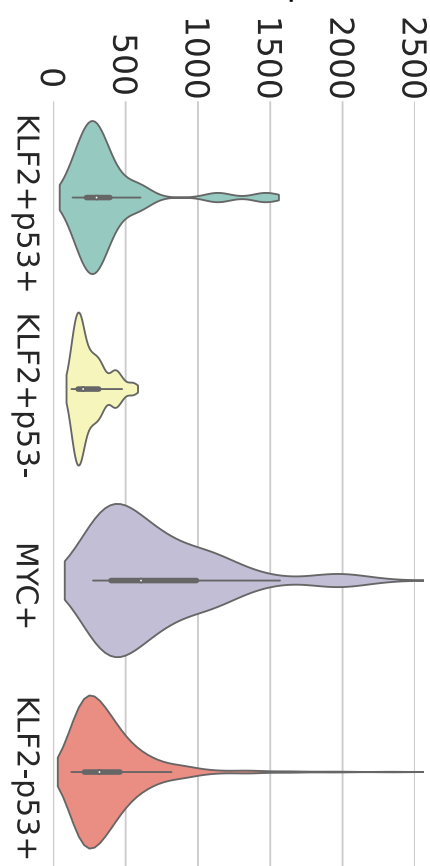
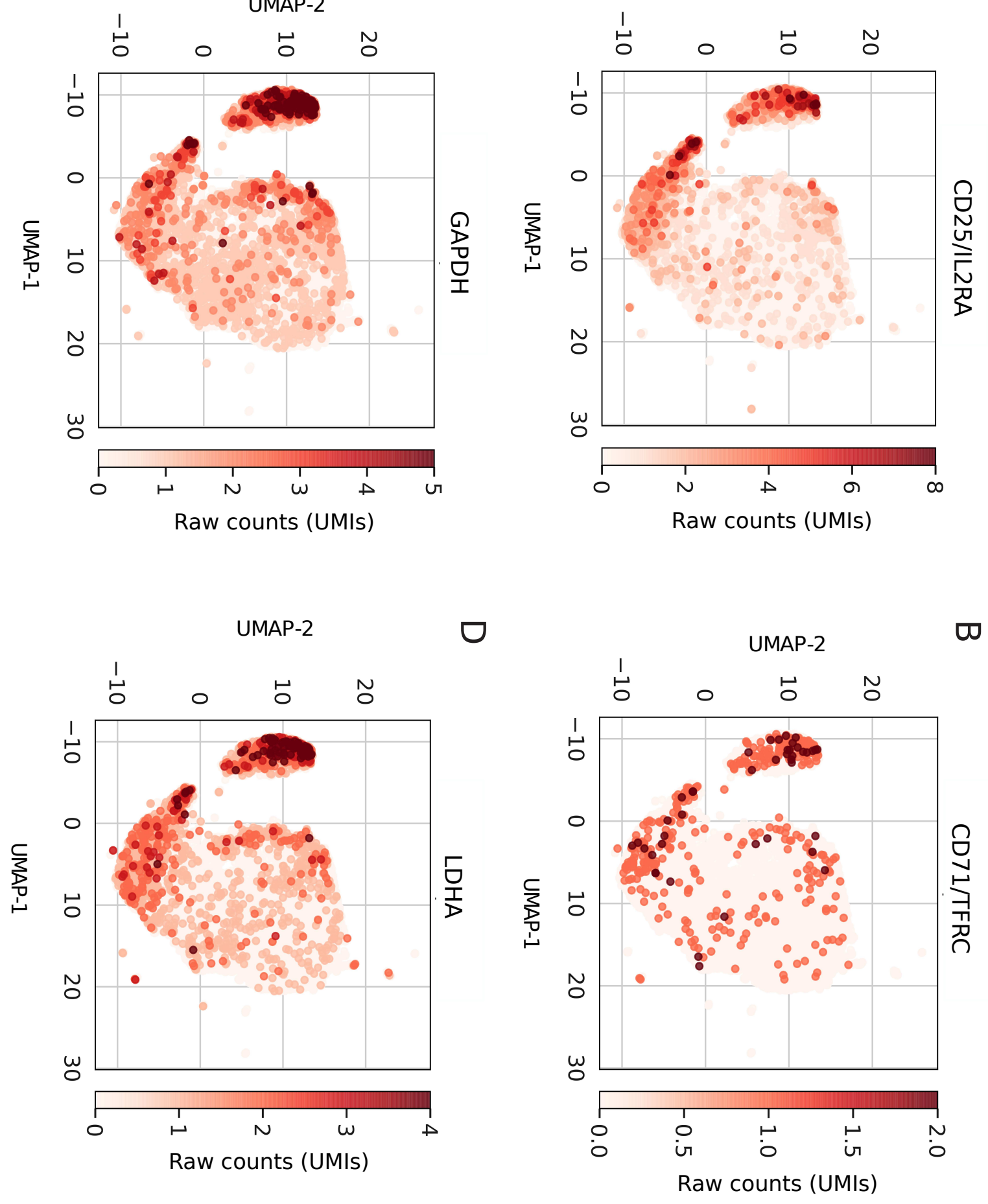


\section{Extended Data Fig. 9.}

A-D. In a UMAP projection of single cell RNA-seq data, cells with high levels of cellular activation markers CD25 and CD71 (A, B) and metabolic markers GAPDH and LDHA (C, D) are found predominantly among uninfected and reactivated HIV+ cell clusters, consistent with the lower proliferation and metabolic activity in +HIV 96 hpi and quiescent cells. E. The total number of UMIs (unique molecular identifiers) per cell, which is an indirect measure of cell size and total number of cellular transcripts, is shown for cells in each category. A smaller value is associated with quiescence in T cells. F. Dual activation of p53 and KLF2 signaling leads to the lowest proviral transcriptional activity even when the HIV counts (UMIs) in each cell are normalized to total counts (UMIs) per cell. 


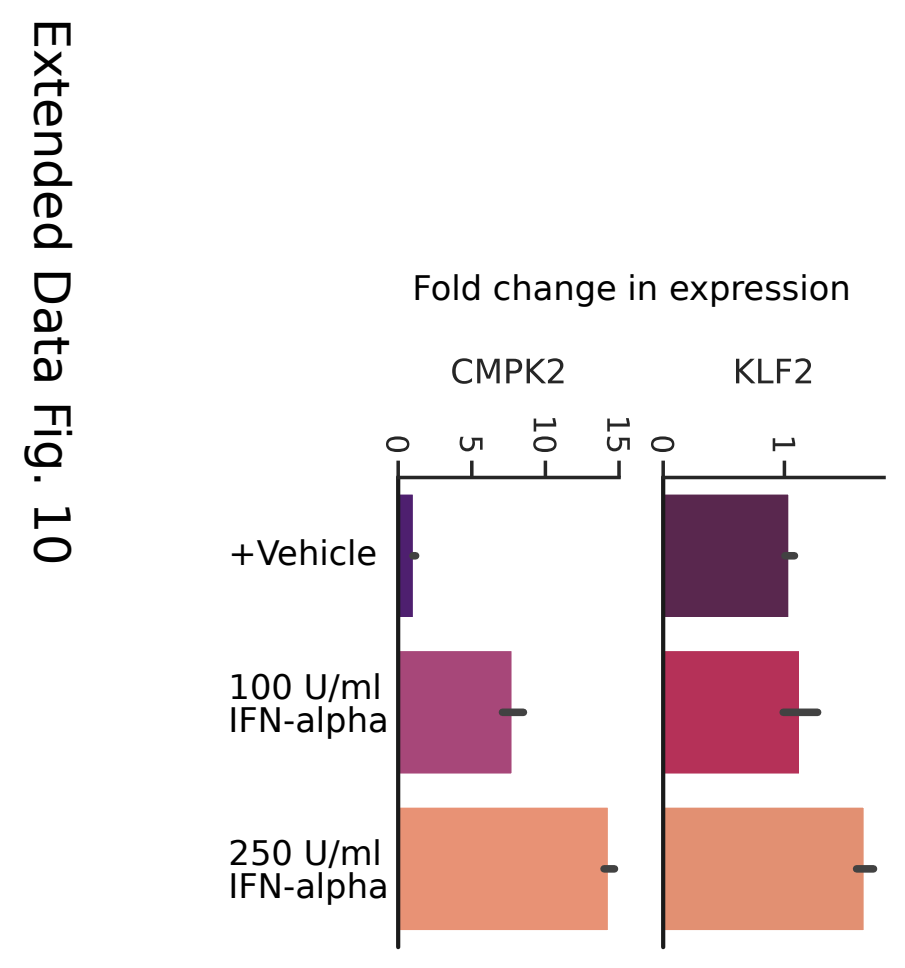


Extended Data Fig. 10.

A. KLF2 is not induced by IFN response. Primary human CD4+ T cells were treated with vehicle, 100 or $250 \mathrm{U} / \mathrm{ml}$ of IFNa for 9 hours, followed by RT-qPCR reactions to measure the expression of KLF2 along with CMPK2, a known IFNa induced gene. 


\section{Supplementary Tables}

Table S1: list of RNA-seq datasets studying the impact of early HIV infection in T cells.

\begin{tabular}{|l|l|l|l|l|}
\hline Accession \# & Cells used & HIV strain used & $\begin{array}{l}\text { Time point after } \\
\text { HIV infection }\end{array}$ & $\begin{array}{l}\text { Reported infection } \\
\text { rate }\end{array}$ \\
\hline PRJNA265857 & Jurkat & HIV-1 NL4-3 & 48 hours & $-70 \%$ \\
\hline PRJNA289529 & H9 & HIV-1 NL4-3 & 7 days & Not reported \\
\hline PRJNA234297 & SUPT1 & HIV-1 LAI & 12 and 24 hours & Close to 100\% \\
\hline PRJNA167037 & SUPT1 & HIV-1 LAI & 12 and 24 hours & Close to 100\% \\
\hline PRJNA482835 & Primary CD4+ T cells & CH077 & 72 hours & $60-80 \%$ \\
\hline PRJNA482835 & Primary CD4+ T cells & STCO1 & 72 hours & $30-60 \%$ \\
\hline This study & Primary CD4+ T cells & $\begin{array}{l}\text { HIV-1 NL4-3, } \\
\text { single round } \\
\text { reporter virus }\end{array}$ & 72 hours & $>95 \%$ \\
\hline
\end{tabular}


Table S2: list of RNA-seq datasets used for studying the impact of MYC knock down.

\begin{tabular}{|l|l|l|l|l|}
\hline Accession \# & Cells used & MYC knockdown method & $\begin{array}{l}\text { Time point after } \\
\text { MYC knockdown }\end{array}$ & $\begin{array}{l}\text { MYC fold } \\
\text { change }\end{array}$ \\
\hline PRJNA492293 & $\begin{array}{l}\text { P493-6 lymphocytes } \\
\text { (Burkitt's lymphoma) }\end{array}$ & $\begin{array}{l}\text { Doxycycline-repressible } \\
\text { MYC transgene }\end{array}$ & 48 hours & -10 \\
\hline PRJNA310128 & U2OS (osteosarcoma) & $\begin{array}{l}\text { Doxycycline-inducible } \\
\text { siMYC vector }\end{array}$ & 28 hours & -2.72 \\
\hline PRJNA390137 & $\begin{array}{l}\text { A375 (malignant } \\
\text { melanoma) }\end{array}$ & $\begin{array}{l}\text { Doxycycline-inducible } \\
\text { shMYC vector }\end{array}$ & 24 hours & -1.45 \\
\hline PRJNA342098 & $\begin{array}{l}\text { HT1080 } \\
\text { (fibrosarcoma) }\end{array}$ & $\begin{array}{l}\text { Doxycycline-inducible } \\
\text { shMYC vector }\end{array}$ & Not reported & -3.51 \\
\hline This study & Primary CD4+ T cells & None & $\begin{array}{l}72 \text { hours post } \\
\text { HIV infection }\end{array}$ & -2.97 \\
\hline
\end{tabular}


Table S3. Reagents used in this study

\begin{tabular}{|c|c|c|}
\hline REAGENT or RESOURCE & SOURCE & IDENTIFIER \\
\hline \multicolumn{3}{|l|}{ Antibodies } \\
\hline AF647 mouse anti-Ki67 & Biolegend & Cat\#350509, RRID:AB_10900810 \\
\hline PE mouse anti-Cyclin D3 & Biolegend & Cat\#684903, RRID:AB_2686979 \\
\hline Rabbit anti-p53 & Abcam & Cat\#ab32389, RRID:AB_776981 \\
\hline AF647 goat anti-rabbit & Abcam & Cat\#ab150079, RRID:AB_2722623 \\
\hline $\begin{array}{l}\text { Dynabeads }{ }^{\mathrm{TM}} \text { Human T- } \\
\text { Activator } \mathrm{CD} 3 / \mathrm{CD} 28\end{array}$ & Thermo Fisher & Cat\#11161D \\
\hline \multicolumn{3}{|l|}{ Biological Samples } \\
\hline $\begin{array}{l}\text { Human peripheral blood } \\
\text { mononuclear cells }\end{array}$ & Allcells & N/A \\
\hline \multicolumn{3}{|c|}{ Chemicals, Peptides, and Recombinant Proteins } \\
\hline IL-2 & $\mathrm{NIH}$ & Cat\#136 \\
\hline TGF- $\beta$ & PeproTech & Cat\#100-21C \\
\hline IL-8 & PeproTech & Cat\#200-08M \\
\hline IL-10 & PeproTech & Cat\#200-10 \\
\hline TRIzol reagent & ThermoFisher & Cat\#15596026 \\
\hline Raltegravir & Millipore Sigma & Cat\#CDS023737 \\
\hline $\begin{array}{l}\text { Fixable Viability Dye } \\
\text { eFluor }{ }^{\mathrm{TM}} 450\end{array}$ & ThermoFisher & Cat\#65-0863-14 \\
\hline Perm/Wash ${ }^{\mathrm{TM}}$ buffer & $\begin{array}{l}\text { BD } \\
\text { Biosciences }\end{array}$ & Cat\#554723 \\
\hline RITA & $\begin{array}{l}\text { Cayman } \\
\text { Chemical }\end{array}$ & Cat $\# 10006426$ \\
\hline Nutlin & $\begin{array}{l}\text { Cayman } \\
\text { Chemical }\end{array}$ & Cat\#18585 \\
\hline Simvastatin & $\begin{array}{l}\text { Cayman } \\
\text { Chemical }\end{array}$ & Cat\#10010344 \\
\hline $\begin{array}{l}\text { MaxCyte electroporation } \\
\text { buffer }\end{array}$ & MaxCyte & N/A \\
\hline $\begin{array}{l}\text { ProLong }{ }^{\mathrm{TM}} \text { Diamond } \\
\text { Antifade Mountant }\end{array}$ & ThermoFisher & Cat\#P36961 \\
\hline Maxima $\mathrm{H}$ minus reverse & ThermoFisher & Cat\#EP0751 \\
\hline
\end{tabular}




\begin{tabular}{|c|c|c|}
\hline \multicolumn{3}{|l|}{ transcriptase } \\
\hline Exonuclease I & $\begin{array}{l}\text { New England } \\
\text { Biolabs }\end{array}$ & Cat\# M0293S \\
\hline \multicolumn{3}{|l|}{ Critical Commercial Assays } \\
\hline $\begin{array}{l}\text { EasySep }{ }^{\mathrm{TM}} \text { Human Naïve } \\
\text { CD4+ T Cell Isolation Kit II }\end{array}$ & $\begin{array}{l}\text { Stem Cell } \\
\text { Technologies }\end{array}$ & Cat\#17555 \\
\hline PrimeScript RT Reagent Kit & TAKARA Bio & Cat\#RR037B \\
\hline $\begin{array}{l}\mathrm{iQ}^{\mathrm{TM}} \text { SYBR } ® \text { Green } \\
\text { Supermix }\end{array}$ & Biorad & Cat\#1708880 \\
\hline $\begin{array}{l}\text { Nextera XT DNA Library } \\
\text { Preparation Kit }\end{array}$ & Illumina & Cat\# FC-131-1024 \\
\hline \multicolumn{3}{|l|}{ Deposited Data } \\
\hline T cell polarization protocol & $\begin{array}{l}\text { (Dobrowolski } \\
\text { et al., 2019) }\end{array}$ & DOI: $10.1128 / \mathrm{mBio} .00337-19$ \\
\hline qPCR protocol & $\begin{array}{l}\text { (Zhang et al., } \\
\text { 2014) }\end{array}$ & DOI: 10.1128/MCB.01673-13 \\
\hline $\begin{array}{l}\text { RNA-seq library preparation } \\
\text { protocol }\end{array}$ & $\begin{array}{l}\text { (Dobrowolski } \\
\text { et al., 2019) }\end{array}$ & DOI: $10.1128 / \mathrm{mBio} .00337-19$ \\
\hline shRNA screen protocol & $\begin{array}{l}\text { (Das et al., } \\
\text { 2018) }\end{array}$ & DOI: 10.1073/pnas.1803468115 \\
\hline mSigDB & $\begin{array}{l}\text { University of } \\
\text { California San } \\
\text { Diego }\end{array}$ & $\begin{array}{l}\text { https://www.gsea-msigdb.org/gsea/msigdb/ } \\
\text { index.jsp }\end{array}$ \\
\hline $\begin{array}{l}\text { Published primary } \\
\text { hematopoietic stem cell } \\
\text { quiescence dataset }\end{array}$ & $\begin{array}{l}\text { (Affer et al., } \\
\text { 2011) }\end{array}$ & ACC\#: GSE24739 \\
\hline $\begin{array}{l}\text { Published iPSC derived } \\
\text { microglia HIV infection } \\
\text { dataset }\end{array}$ & $\begin{array}{l}\text { (Ryan et al., } \\
\text { 2020) }\end{array}$ & ACC\#: GSE143687 \\
\hline $\begin{array}{l}\text { Published primary CD4+ T } \\
\text { cell ex-vivo HIV latency } \\
\text { dataset }\end{array}$ & $\begin{array}{l}\text { (Trypsteen et } \\
\text { al., 2019) }\end{array}$ & ACC\#: PRJNA322599 \\
\hline $\begin{array}{l}\text { Published primary CD4+ T } \\
\text { cell ex-vivo HIV latency } \\
\text { dataset }\end{array}$ & $\begin{array}{l}\text { Institute of } \\
\text { Microbiology }\end{array}$ & ACC\#: PRJNA376596 \\
\hline $\begin{array}{l}\text { Published primary CD4+ T } \\
\text { cell activation time course } \\
\text { dataset }\end{array}$ & $\begin{array}{l}\text { Johnson \& } \\
\text { Johnson }\end{array}$ & ACC\#: PRJNA209867 \\
\hline $\begin{array}{l}\text { Published SUPT1 HIV } \\
\text { infection dataset }\end{array}$ & $\begin{array}{l}\text { (Chang et al., } \\
\text { 2011) }\end{array}$ & ACC\#: PRJNA167037 \\
\hline
\end{tabular}




\begin{tabular}{|c|c|c|}
\hline $\begin{array}{l}\text { Published SUPT1 HIV } \\
\text { infection dataset }\end{array}$ & $\begin{array}{l}\text { (Peng et al., } \\
\text { 2014) }\end{array}$ & ACC\#: PRJNA234297 \\
\hline $\begin{array}{l}\text { Published H9 HIV infection } \\
\text { dataset }\end{array}$ & $\begin{array}{l}\text { (Gupta et al., } \\
\text { 2015) }\end{array}$ & ACC\#: PRJNA289529 \\
\hline $\begin{array}{l}\text { Published Jurkat HIV } \\
\text { infection dataset }\end{array}$ & $\begin{array}{l}\text { Lady Davis } \\
\text { Institute for } \\
\text { Medical } \\
\text { Research }\end{array}$ & ACC\#: PRJNA265857 \\
\hline $\begin{array}{l}\text { Published STCO1 and } \\
\text { CH077 HIV infection } \\
\text { dataset }\end{array}$ & $\begin{array}{l}\text { (Langer et al., } \\
\text { 2019) }\end{array}$ & ACC\#: PRJNA482835 \\
\hline $\begin{array}{l}\text { Published primary CD4+ T } \\
\text { cell HIV infection dataset }\end{array}$ & $\begin{array}{l}\text { University of } \\
\text { Pennsylvania }\end{array}$ & ACC\#: PRJNA277687 \\
\hline Gencode release 27 & $\begin{array}{l}\text { Wellcome } \\
\text { Sanger } \\
\text { Institute }\end{array}$ & $\begin{array}{l}\text { https://www.gencodegenes.org/human/ } \\
\text { release_27.html }\end{array}$ \\
\hline HIV reporter virus protocol & $\begin{array}{l}\text { (Dobrowolski } \\
\text { et al., 2019) }\end{array}$ & DOI: $10.1128 / \mathrm{mBio} .00337-19$ \\
\hline $\begin{array}{l}\text { Transcriptome of human } \\
\text { primary CD4+ T cells } \\
\text { before and after HIV } \\
\text { infection, quiescence and } \\
\text { reactivation }\end{array}$ & $\begin{array}{l}\text { Sequence } \\
\text { Read Archive }\end{array}$ & SRP145508 \\
\hline \multicolumn{3}{|c|}{ Experimental Models: Cell Lines } \\
\hline Jurkat cells & ATCC & Cat\#TIB-152 \\
\hline \multicolumn{3}{|l|}{ Oligonucleotides } \\
\hline $\begin{array}{l}\text { Scrambled Negative } \\
\text { Control DsiRNA }\end{array}$ & IDT & Cat\#51-01-19-08 \\
\hline $\begin{array}{l}\text { TEX } 615 \text { Transfection } \\
\text { Control DsiRNA }\end{array}$ & IDT & Cat\#51-01-20-21 \\
\hline MYC targeting dsiRNA \#1 & This paper & $\begin{array}{l}\text { 5'-AUCAUUGAGCCAAAUCUUAAAAAAA } \\
\text { 5'- } \\
\text { UUUUUUUAAGAUUUGGCUCAAUGAUAU }\end{array}$ \\
\hline MYC targeting dsiRNA \#2 & This paper & $\begin{array}{l}\text { 5'-CGACGAGACCUUCAUCAAAAACATC } \\
\text { 5'- } \\
\text { GAUGUUUUUGAUGAAGGUCUCGUCGUC }\end{array}$ \\
\hline KLF2 targeting dsiRNA \#1 & This paper & $\begin{array}{l}\text { 5'-GUGCAAUAAUUUAAGUGG } \\
\text { 5'-GAAGAUGCCACUUAAAUU }\end{array}$ \\
\hline KLF2 targeting dsiRNA \#2 & This paper & $\begin{array}{l}\text { 5'-CGAGGCUUGUGAUGCCU } \\
\text { 5'-UUCUCACAAGGCAUCACA }\end{array}$ \\
\hline Barcoded Bead SeqB & ChemGenes & Macosko-2011-10B \\
\hline
\end{tabular}




\begin{tabular}{|c|c|c|}
\hline \multicolumn{3}{|l|}{ Software and Algorithms } \\
\hline Fastqc & $\begin{array}{l}\text { Babraham } \\
\text { Bioinformatics }\end{array}$ & $\begin{array}{l}\text { https://www.bioinformatics.babraham.ac.uk/ } \\
\text { projects/fastqc/ }\end{array}$ \\
\hline $\begin{array}{l}\text { Gene Set Enrichment } \\
\text { Analysis (GSEA) package }\end{array}$ & $\begin{array}{l}\text { University of } \\
\text { California San } \\
\text { Diego }\end{array}$ & https://www.gsea-msigdb.org/gsea/index.jsp \\
\hline Trim Galore & $\begin{array}{l}\text { Babraham } \\
\text { Bioinformatics }\end{array}$ & $\begin{array}{l}\text { https://www.bioinformatics.babraham.ac.uk/ } \\
\text { projects/trim_galore/ }\end{array}$ \\
\hline STAR version $2.7 .2 \mathrm{~b}$ & $\begin{array}{l}\text { (Dobin and } \\
\text { Gingeras, } \\
\text { 2015) }\end{array}$ & https://github.com/alexdobin/STAR \\
\hline htseq-count & $\begin{array}{l}\text { (Anders et al., } \\
\text { 2015) }\end{array}$ & $\begin{array}{l}\text { https://htseq.readthedocs.io/en/ } \\
\text { release_0.11.1/install.html }\end{array}$ \\
\hline Kallisto version 0.43 .1 & $\begin{array}{l}\text { (Bray et al., } \\
\text { 2016) }\end{array}$ & https://pachterlab.github.io/kallisto/download \\
\hline Sleuth & $\begin{array}{l}\text { (Pimentel et } \\
\text { al., 2017) }\end{array}$ & https://pachterlab.github.io/sleuth/download \\
\hline edgeR & $\begin{array}{l}\text { (Robinson et } \\
\text { al., 2010) }\end{array}$ & $\begin{array}{l}\text { https://bioconductor.org/packages/release/ } \\
\text { bioc/html/edgeR.html }\end{array}$ \\
\hline
\end{tabular}

